\title{
Follow-up investigation and detailed mutational characterization of the SARS-CoV-2 Omicron variant lineages (BA.1, BA.2, BA.3 and BA.1.1) \\ Qussai Abbas ${ }^{1}$, Alexey Kusakin ${ }^{1}$, Kinda Sharrouf ${ }^{1}$, Susan Jyakhwo ${ }^{1}$, and Aleksey S Komissarov ${ }^{1 *}$
}

1 Applied Genomics Laboratory, SCAMT Institute, ITMO University, Lomonosova 9 Str., Saint Petersburg 197101, Russia

* ad3002@gmail.com

\begin{abstract}
Aided by extensive protein mutations, the SARS-CoV-2 Omicron (B.1.1.529) variant overtook the previously dominant Delta variant and rapidly spread around the world. It was shown to exhibit significant resistance to current vaccines and evasion from neutralizing antibodies. It is therefore critical to investigate the Omicron mutations' trajectories. In this study, a literature search of published articles and SARS-CoV-2 databases was conducted, We explored the full list of mutations in Omicron BA.1, BA.1.1, BA.2, and BA.3 lineages. We described in detail the prevalence and occurrence of the mutations across variants, and how Omicron differs from them. We used GISAID as our primary data source, which provides open-access to genomics data of the SARS-CoV-2 virus, in addition to epidemiological and geographical data. We examined how these mutations interact with each other, their co-occurrence and clustering. Our study offers for the first time a comprehensive description of all mutations with a focus on non-spike mutations and demonstrated that mutations in regions other than the Spike $(\mathrm{S})$ genes are worth investigating further. Our research established that the Omicron variant has retained some mutations reported in other SARS-CoV-2 variants, yet many of its mutations are extremely rare in other variants and unique to Omicron. Some of these mutations have been linked to the transmissibility and immune escape of the virus, and indicate a significant shift in SARS-CoV-2 evolution. The most likely theories for the evolution of the Omicron variant were also discussed.
\end{abstract}

\section{Keywords:}

SARS-CoV-2, COVID-19, Coronavirus, Mutations, Omicron, Omicron origin, clade, Variant, lineage, BA.1, BA.1.1, BA.2, BA.3, Pandemic.

\section{Introduction}

Severe acute respiratory syndrome coronavirus 2 (SARS-CoV-2) is the causative agent of COVID-19, which emerged in December 2019 and it continued to evolve, creating different variants of progressively increased transmissibility between humans [1]. SARSCoV-2 is an enveloped, positive-sense, single-stranded RNA virus with a genome size of about 30,000 base pairs of genus Betacoronavirus [2] Genetic lineages of SARS-CoV-2 
have been emerging and circulating the world since the beginning of the COVID-19 pandemic. Globally, various COVID-19 variants exist and some may become a concern to public health. Consequently, WHO designated SARS-CoV-2 variants of concern (VOCs) based on their high transmission rate, potential immune evasion, unusual epidemiological properties, or adverse impact on diagnostics and therapeutics. WHO also designated SARS-CoV-2 variants of interest (VOIs), depending on the fact that these variants have specific genetic markers, which are predicted or known to affect virus characteristics. So far, there are five main VOCs, Alpha (B.1.1.7), Beta (B.1.351), Gamma (P.1), Delta (B.1.617.2), and Omicron (B.1.1.529) 3]. There are also three VOIs, Lambda (C.37), $\mathrm{Mu}$ (B.1.621), and AY.4.2 [4]. Further information about VOCs and VOIs are shown in Supplementary Table 2

The omicron variant (B.1.1.529) was first detected in South Africa and was reported to WHO on the 24th of November 2021 and designated as VOC on the 26th of November 2021 [4]. As of the 7th of January 2022, this variant has been confirmed in 135 countries [5], and the infected cases are the highest in the United Kingdom followed by the USA 6 .

By comparing with the reference SARS-CoV-2 Wuhan-Hu-1 genome, there are more than 50 mutations in the genome of Omicron variant compared to other variants of concern. Substitution and deletion mutations are common in SARS-CoV-2 variants, but the insertion mutation (ins214EPE) has been observed for the first time in the Omicron lineages 7 .

Several of these mutations are shared with previous VOCs, and some of them are associated with the increased ability to bind to the ACE2 receptor protein or involved in host immune system invasion 8 [11].

Omicron variant possesses comparable binding affinity to human ACE2 in comparison with the wild type SARS-CoV-2, but much weaker binding affinity than Delta variant [12. Recent study suggests that new mutations in Omicron variant contribute to transmission advantages, immune escape, and novel spike functionality [13, 14. As of early February 2022, 8,609,048 SARS-COV-2 virus sequences have been submitted to the GISAID database [15]. Out of them 1,622,178 sequences are for the Omicron variant. Analyzing that many sequences is a bit of a technical challenge. World map epidemiology and geographic trajectories of Omicron mutations are available on the Nextstrain website [16].

\section{Various nomenclatures for Omicron}

Omicron corresponds to Pango lineage B.1.1.529 and includes descendent Pango lineages BA.1, BA.1.1, BA.2 and BA.3 17. The Nextstrain project has assigned Omicron the clade identifier "21M" and inside this group assigned "21K" for "BA.1" and "21L" for "BA.2" 18. The GISAID project has assigned it the clade identifier "GRA" 15.

\section{Omicron lineages}

The three lineages of the Omicron variant (BA.1, BA.2, and BA.3) were first detected at approximately the same time and from the same place.

- BA.1 lineage was first identified on the 11th of November 2021, (Africa / Botswana / South East / Greater Gaborone / Gaborone), Accession ID on GISAID is [EPI_ISL_6640916].

- BA.2 lineage was first identified on the 17th of November 2021, (Africa / South Africa / Gauteng / Tshwane), Accession ID on GISAID is [EPI_ISL_6795834.2]. 
- BA.3 lineage was first identified on the 18th of November 2021, (Africa / South Africa / North West), Accession ID on GISAID is [EPI_ISL_7605713].

- BA.1.1 is a BA.1 sub-lineage, and it differs from BA.1 only in one mutation in spike protein (R346K), which also occurs in the Mu variant. The number of BA.1.1 cases started to increase since the 8th of December 2021.

BA.1 is highly resistant to antiviral drugs and vaccine-induced humoral immunity. As well as, the Spike protein of BA.1 is less efficiently cleaved by furin and less fusogenic than those of Delta and an ancestral SARS-CoV-2 belonging to the B.1.1 lineage [19 20. Additionally, the pathogenicity of BA.1 is attenuated when compared to Delta and an ancestral B.1.1 virus 19 20. When compared to BA.1, Yamasoba et al. found that the BA.2 lineage has a higher effective reproduction number, higher fusogenicity, and higher pathogenicity, which supports the statistical findings that BA.2 has a 1.4 times higher effective reproductive number than BA.1. The team of Yamasoba et al. also showed that BA.2 is resistant to the humoral immunity induced by BA.1 20. In addition, the Omicron lineages (BA.1.1, BA.2, and BA.3) are likely more transmissible than omicron (BA.1) and Delta [21].

\section{The origin of the Omicron variant have been a subject of controversy}

All viruses evolve over time, mutate, and new variants may occur with an increase in transmissibility, or an increase in virulence. Some variants may diverge early from other strains. The ability of viruses to adapt to new hosts and environments is enormously dependent on their capacity to generate de novo diversity in a short period. Spontaneous mutation rates vary among viruses. It is well established that RNA viruses mutate faster than DNA viruses, single-stranded viruses mutate faster than double-stranded viruses, and genome size appears to correlate negatively with mutation rate 22 . Omicron is so different from the millions of SARS-CoV-2 genomes that have been shared publicly that pinpointing its closest relative is difficult. Thus, it is crucial to identify the origin of the Omicron virus variant and how this heavily mutated variant develop.

There are mainly three explanations for how the Omicron variant may appear (Fig 1). The first theory proposes that Omicron could be developed and significantly mutated in an immune-suppressed patient, such as someone with HIV(Fig 1A). Previous research has revealed that immunocompromised individuals can serve as reservoirs for novel viral variants, such as human norovirus and influenza 24,25. Because South Africa has the world's largest HIV epidemic, some experts speculated that Omicron originated there because it was first discovered there. The idea is bolstered by the sequencing of SARS-CoV-2 samples from some chronically infected patients, and the evidence is supported by the fact that persistent SARS-CoV-2 infections in immunocompromised patients can trigger the accumulation of an unusually high variety of mutations with potential relevance at both biological and epidemiological levels 26 29]. A recent study by Kemp, S. et al. found that chronic infection with SARS-CoV-2 led to viral evolution and impaired sensitivity to neutralizing antibodies in an immunosuppressed individual treated with convalescent plasma 30. The study of Bazykin G. et al. reported an accumulation of 18 mutations de novo in the coronavirus samples from an immunodeficient patient (a lymphoma patient) 29]. These mutations accumulated through a 132day observation period, which is exceeding the average rate of evolution of SARSCoV-2. Interestingly, $\mathrm{S}: \Delta \mathrm{H} 69 / \Delta \mathrm{V} 70$ and $\mathrm{S}: \mathrm{Y} 453 \mathrm{~F}$ mutations (the $\Delta \mathrm{F}$ combination) were responsible for the bulk of positive samples. Y453F affects the receptor-binding 


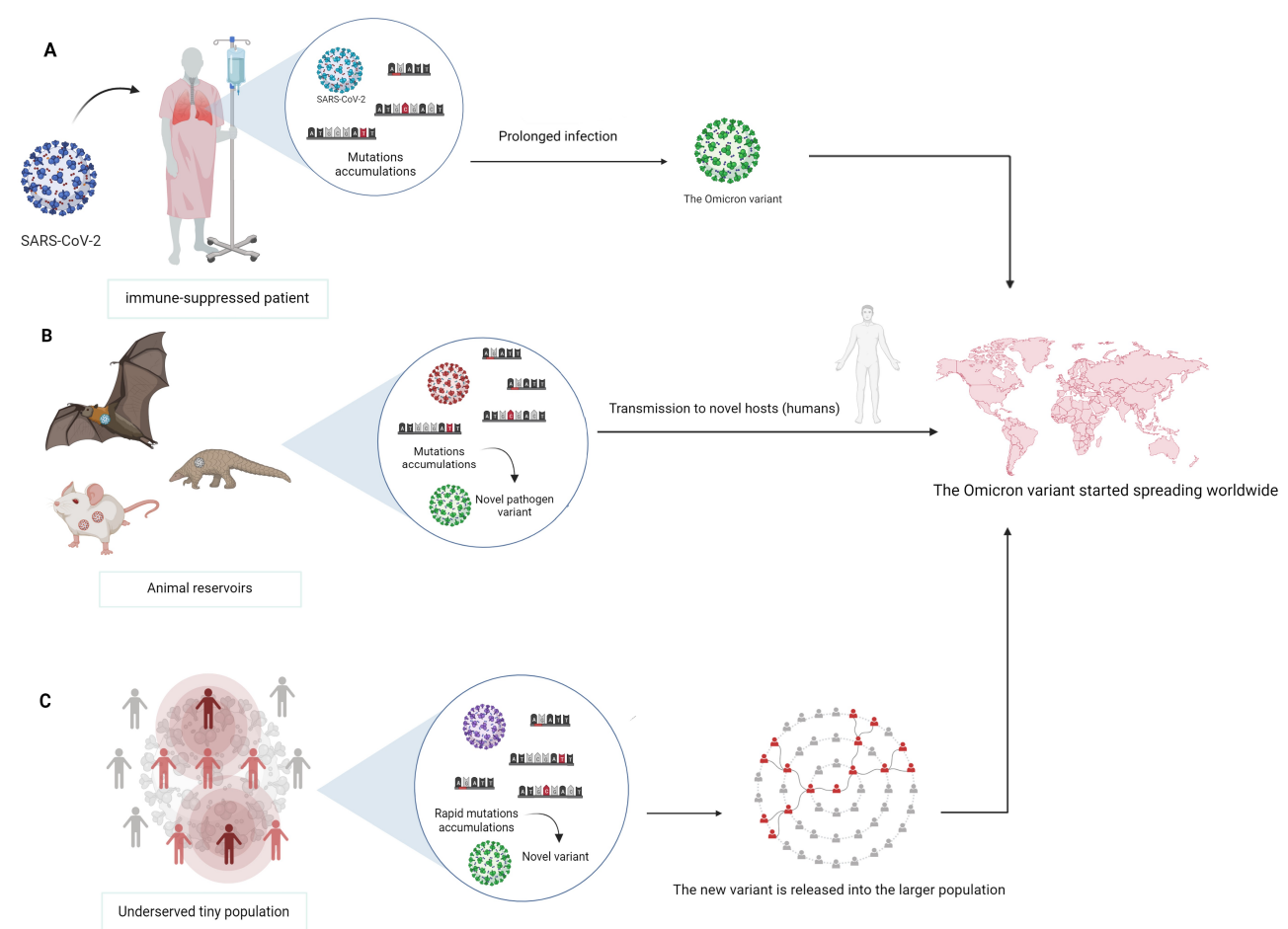

Fig 1. The three most likely scenarios for how the Omicron variant appeared. A: Omicron could have developed and significantly mutated in an immune-suppressed patient with prolonged viral infections. B: The Omicron variant might have evolved in non-human reservoirs, such as animal source, and as of late spread from it to humans. $\mathrm{C}$ : The virus might began circulating and changing in underserved places with a tiny population, where it had the opportunity to mutate rapidly, it could then have been released into the larger population, where it could have spread to different groups. Created with BioRender [23].

domain (RBD), possibly increasing human angiotensin-converting enzyme 2 (hACE2) binding 31. It allows immune escape from monoclonal antibodies and polyclonal sera. $\Delta \mathrm{H} 69 / \Delta \mathrm{V} 70$ is also involved in the evasion of neutralising antibodies [30]. In other similar studies conducted by Borges V. et al. 28] and Karim F. et al. [27] it has been observed a concurrent accumulation of mutations de novo in the SARS-CoV2 genome of immunocompromised patients (non-Hodgkin lymphoma patient under immunosuppressive therapy and advanced HIV patient with antiretroviral treatment failure, respectively) with a persistent SARS-CoV-2 infection over at least 6 months. The emerged mutations are potentially associated with immune evasion and/or enhanced transmission, primarily targeting the SARS-CoV-2 key host-interacting protein and antigen. Recent research has also demonstrated that immunocompromised paediatric and young adult patients are susceptible to prolonged viral infections with prolonged infectious virus shedding and mutation accumulation. The reported results support a potential correlation between host immune response and the emergence of viral variants, which may have the potential to escape antibody neutralisation [26]. These findings provide support to the hypothesis of intra-host evolution as one mechanism for the emergence of SARS-CoV-2 variants with immune evasion properties.

Alternatively, the Omicron variant might have evolved in non-human reservoirs, such as animal source, and as of late spread from it to humans(Fig 1B). Researchers have recently found evidence to support omicron's potential origin in mice. The result of 
the team of professor Jianguo Xu suggests that omicron variant may evolve in mouse host. They discover 5 mouse-adapted mutation sites (K417, E484, Q493, Q498, and N501) in viral S protein suggesting mouse as intermediate host 32]. During evolution in mice, omicron adapted in host body by acquiring amino acid mutation in spike protein that enhanced binding with mouse ACE2 receptor [33,34]. A recent study suggests that the Omicron variant has been around for much longer than predicted, given its close relationship to the Alpha variant 35 .

Instead, the virus may have began circulating and changing in underserved places with a tiny population, where it had the opportunity to mutate rapidly in comparison to variations outside of that bubble (Fig $1 \mathrm{C}$ ). It could then have been released into the larger population, where it could have spread to different groups. But that begs the issue of where Omicron's predecessors were for all of that period, and is there someplace isolated enough for this sort of virus to transmit for that long without resurfacing in other places.

A recent study proposed that the Omicron "ins214EPE" insertion could have evolved in a co-infected individual. The study suggested that the nucleotide sequence encoding for ins214EPE could have been acquired by template switching involving the genomes of other viruses that infect the same host cells as SARS-CoV-2 or the human transcriptome of host cells infected with SARS-CoV-2 7].

\section{Characterization of Omicron variant mutations}

A vast and unprecedented number of mutations has accumulated in the Omicron lineages (BA.1, BA.2, and BA.3). These mutations spread over the genome, including Spike, and non-Spike regions. Some of these mutations are not unique to the Omicron variant; rather, some can be found in other VOCs or VOIs. Out of the 82 mutations, 24 mutations were found to be present in at least one additional variant. Consequently, 58 mutations have not been identified in any VOCs or VOIs, which make them "Omicron specific mutations". In fact, the vast majority of mutations outside the Spike protein have not been identified in the previous VOCs or VOIs. After the investigation on the first occurrence place/time of each mutation (Table 1), it was revealed that several mutations appeared for the first time in North America (24 mutations). Others appeared for the first time in Asia, Europe, Africa, South America, or Oceania (19, 18, 12, 5, and 3 mutations, respectively). Interestingly, the bulk of these mutations first appeared in the first four months of 2020 (60 mutations in total).

The different Omicron lineages (BA.1, BA.2 and BA.3) share 33 mutations (ORF1a:T3255I, ORF1a:P3395H, ORF1a:A3675/3677, ORF1b:P314L, ORF1b:I1566V, S:G142D, S:G339D, S:S373P, S:S375F, S:K417N, S:N440K, S:S477N, S:T478K, S:E484A, S:Q493R, S:Q498R, S:N501Y, S:Y505H, S:D614G, S:H655Y, S:N679K, S:P681H, S:N764K, S:D796Y, S:Q954H, S:N969K, E:T9I, M:Q19E, M:A63T, N:P13L, N:s31/33, N:R203K, N:G204R). On the other hand, 15 mutations are unique to their lineages. Most of them (13 mutations) corresponds to the BA.2 lineage (ORF1a:T842I, ORF1a:L3027F, ORF1a:T3090I, ORF1a:L3201F, ORF1a:F3677L, ORF1b:R1315C, ORF1b:T2163I, S:T19I, S:LPPA24Sdel, S:V213G, S:T376A, S:R408S, ORF6:D61L). BA.3 possesses a unique mutation in NSP6:A88V. And only 1 mutation is distinctive to the sub-lineage BA.1.1 (S:R346K). It is notable that the BA.3 lineage has mutations shared with both BA.1 (and its BA.1.1 sub-lineage) and BA.2. However, it is closer to the BA.1 and BA.1.1 because it possesses S: $\Delta 69 / 70, \mathrm{~S}: \Delta 143 / 145$ and S:NL211I deletions, which are not present in BA.2. Detailed annotation of the positions of Omicron mutations are shown in Supplementary Table 1. 
bioRxiv preprint doi: https://doi.org/10.1101/2022.02.25.481941; this version posted February $26,2022$. The copyright holder for this preprint (which was not certified by peer review) is the author/funder. All rights reserved. No reuse allowed without permission.

Table 1. Omicron variant mutations prevalence and occurrence across variants.

NTD: N-terminal domain; RBD: receptor-binding domain; RBM: receptor-binding motif; PBCS: poly-basic cleavage site; SD1/SD2: subdomain 1/subdomain 2; CTD: C-terminal domain.

\begin{tabular}{|c|c|c|c|c|c|}
\hline Mutation & $\begin{array}{c}\text { Omicron } \\
\text { lineage with } \\
\text { the mutation }\end{array}$ & $\begin{array}{c}\text { SARS-CoV-2 } \\
\text { variants } \\
\text { sharing the } \\
\text { mutation with } \\
\text { omicron } \\
\text { variant (VOC, } \\
\text { VOI) }\end{array}$ & $\begin{array}{c}\text { First } \\
\text { occurrence } \\
\text { place }\end{array}$ & $\begin{array}{c}\text { Collection } \\
\text { date }\end{array}$ & $\begin{array}{c}\text { Accession ID of } \\
\text { the first detected } \\
\text { viral sequence } \\
\text { with the } \\
\text { mutation } \\
\text { (GISAID) }\end{array}$ \\
\hline \multicolumn{6}{|l|}{ NSP1 } \\
\hline S135R & BA.2 and BA. 3 & - & Asia / Armenia & $2020-08-03$ & EPI_ISL_1854612 \\
\hline \multicolumn{6}{|l|}{ NSP3 } \\
\hline T24I & BA.2 & - & $\begin{array}{c}\text { Asia / Saudi } \\
\text { Arabia / Makkah }\end{array}$ & 2020-04-06 & EPI_ISL_437704 \\
\hline K38R & BA.1 and BA.1.1 & - & $\begin{array}{c}\text { North America / } \\
\text { Canada / } \\
\text { Ontario }\end{array}$ & $2020-02$ & EPI_ISL_418325 \\
\hline G489S & BA. 2 and BA. 3 & - & $\begin{array}{l}\text { Asia / China / } \\
\text { Guangdong / } \\
\text { Dongguan }\end{array}$ & $2020-01-26$ & EPI_ISL_428466 \\
\hline S1265del & BA.1 and BA.1.1 & - & $\begin{array}{c}\text { South America / } \\
\text { Brazil / Sao } \\
\text { Paulo / Sao Jose } \\
\text { dos Campos }\end{array}$ & 2020-03-09 & EPI_ISL_875545 \\
\hline 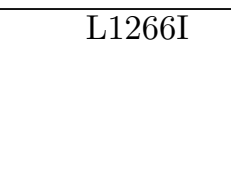 & BA.1 and BA.1.1 & - & $\begin{array}{c}\text { South America / } \\
\text { Brazil / Sao } \\
\text { Paulo / Sao Jose } \\
\text { dos Campos }\end{array}$ & 2020-03-09 & EPI_ISL_875545 \\
\hline $\mathrm{A} 1892 \mathrm{~T}$ & BA.1 and BA.1.1 & - & $\begin{array}{l}\text { North America / } \\
\text { USA / New York } \\
\text { / Erie County }\end{array}$ & $2020-04-17$ & EPI_ISL_1009376 \\
\hline \multicolumn{6}{|l|}{ NSP4 } \\
\hline L264F & BA.2 & - & $\begin{array}{c}\text { Europe / Italy / } \\
\text { Lombardy }\end{array}$ & $2020-02-23$ & EPI_ISL_542227 \\
\hline T327I & BA.2 and BA. 3 & - & $\begin{array}{c}\text { Asia / China / } \\
\text { Hubei / Wuhan }\end{array}$ & $2019-12-30$ & EPI_ISL_402130 \\
\hline $\mathrm{L} 438 \mathrm{~F}$ & BA.2 & - & $\begin{array}{c}\text { North America / } \\
\text { USA / } \\
\text { Washington }\end{array}$ & $2020-03-13$ & EPI_ISL_430895 \\
\hline T492I & $\begin{array}{c}\text { BA.1, BA.2, } \\
\text { BA.1.1, and } \\
\text { BA.3 }\end{array}$ & $\begin{array}{l}\text { Delta, } \mathrm{Mu}, \\
\text { Lambda } 36 .\end{array}$ & Asia / Georgia & $2020-02-28$ & EPI_ISL_2896261 \\
\hline \multicolumn{6}{|l|}{ NSP5 } \\
\hline $\mathrm{P} 132 \mathrm{H}$ & $\begin{array}{l}\text { BA.1, BA.2, } \\
\text { BA.1.1, and } \\
\text { BA.3 }\end{array}$ & - & $\begin{array}{c}\text { North America / } \\
\text { USA / Texas / } \\
\text { Houston }\end{array}$ & $2020-07-20$ & EPI_ISL_5073555 \\
\hline \multicolumn{6}{|l|}{ NSP6 } \\
\hline A $88 \mathrm{~V}$ & BA.3 & - & $\begin{array}{l}\text { Europe / Poland } \\
\text { / Zachodniopo- } \\
\text { morskie }\end{array}$ & 2020-01-14 & EPI_ISL_2631277 \\
\hline
\end{tabular}


bioRxiv preprint doi: https://doi.org/10.1101/2022.02.25.481941; this version posted February 26, 2022. The copyright holder for this preprint (which was not certified by peer review) is the author/funder. All rights reserved. No reuse allowed without permission.

\begin{tabular}{|c|c|c|c|c|c|}
\hline S106del & $\begin{array}{l}\text { BA.1, BA.2, } \\
\text { BA.1.1, and } \\
\text { BA. } 3\end{array}$ & $\begin{array}{l}\text { Alpha, Beta, } \\
\text { Gamma 36] }\end{array}$ & $\begin{array}{l}\text { North America / } \\
\text { USA / New York }\end{array}$ & $2020-01-28$ & EPI_ISL_3364539 \\
\hline G107del & $\begin{array}{l}\text { BA.1, BA.2, } \\
\text { BA.1.1, and } \\
\text { BA.3 }\end{array}$ & $\begin{array}{l}\text { Alpha, Beta, } \\
\text { Gamma 36. }\end{array}$ & $\begin{array}{l}\text { North America / } \\
\text { USA / New York }\end{array}$ & $2020-01-28$ & EPI_ISL_3364539 \\
\hline F108del & $\begin{array}{c}\text { BA.1, BA.2, } \\
\text { BA.1.1, and } \\
\text { BA.3 }\end{array}$ & $\begin{array}{l}\text { Alpha, Beta, } \\
\text { Gamma 36. }\end{array}$ & $\begin{array}{l}\text { North America / } \\
\text { USA / New York }\end{array}$ & $2020-01-28$ & EPI_ISL_3364539 \\
\hline $\mathrm{I} 189 \mathrm{~V}$ & BA.1 and BA.1.1 & - & Europe / Ireland & $2020-03-10$ & EPI_ISL_5248210 \\
\hline \multicolumn{6}{|c|}{ NSP12 (RdRp) } \\
\hline P323L & $\begin{array}{c}\text { BA.1, BA.2, } \\
\text { BA.1.1, and } \\
\text { BA. } 3\end{array}$ & $\begin{array}{c}\text { Alpha, Beta, } \\
\text { Gamma, Delta, } \\
\text { Mu, Lambda } 36\end{array}$ & $\begin{array}{c}\text { Africa / Niger / } \\
\text { Niamey }\end{array}$ & $2020-01-01$ & EPI_ISL_3804266 \\
\hline \multicolumn{6}{|l|}{ NSP13 } \\
\hline $\mathrm{R} 392 \mathrm{C}$ & BA.2 & - & $\begin{array}{c}\text { Asia / China / } \\
\text { Hubei / Wuhan }\end{array}$ & $2020-01-26$ & EPI_ISL_493181 \\
\hline \multicolumn{6}{|l|}{ NSP14 } \\
\hline $\mathrm{I} 42 \mathrm{~V}$ & $\begin{array}{l}\text { BA.1, BA.2, } \\
\text { BA.1.1, and } \\
\text { BA. } 3\end{array}$ & - & $\begin{array}{l}\text { Asia / United } \\
\text { Arab Emirates }\end{array}$ & $2020-03-15$ & EPI_ISL_435127 \\
\hline \multicolumn{6}{|l|}{ NSP15 } \\
\hline $\mathrm{T} 112 \mathrm{I}$ & BA.2 & - & $\begin{array}{c}\text { North America / } \\
\text { USA / Florida }\end{array}$ & $2020-03-19$ & EPI_ISL_1379452 \\
\hline \multicolumn{6}{|c|}{ Spike protein (NTD) } \\
\hline $\mathrm{T} 19 \mathrm{I}$ & BA.2 & - & $\begin{array}{l}\text { North America / } \\
\text { USA / Colorado }\end{array}$ & $2020-03-17$ & EPI_ISL_5439308 \\
\hline L24S & BA.2 & - & $\begin{array}{c}\text { North America / } \\
\text { USA / } \\
\text { Washington }\end{array}$ & $2020-03-17$ & EPI_ISL_570806 \\
\hline P25del & BA.2 & - & $\begin{array}{c}\text { South America / } \\
\text { Brazil / Rio de } \\
\text { Janeiro }\end{array}$ & $2020-04-17$ & EPI_ISL_1691459 \\
\hline P26del & BA.2 & - & $\begin{array}{c}\text { South America / } \\
\text { Brazil / Rio de } \\
\text { Janeiro }\end{array}$ & $2020-04-17$ & EPI_ISL_1691459 \\
\hline A27del & BA.2 & - & $\begin{array}{c}\text { South America / } \\
\text { Brazil / Rio de } \\
\text { Janeiro }\end{array}$ & $2020-04-17$ & EPI_ISL_1691459 \\
\hline $\mathrm{A} 67 \mathrm{~V}$ & $\begin{array}{c}\text { BA.1, BA.3, and } \\
\text { BA.1.1 }\end{array}$ & Eta 37 & $\begin{array}{l}\text { Europe / Spain / } \\
\text { Madrid / Madrid }\end{array}$ & $2020-03-12$ & EPI_ISL_779718 \\
\hline H69del & $\begin{array}{c}\text { BA.1, BA.3, and } \\
\text { BA.1.1 }\end{array}$ & Alpha, Eta 37 & $\begin{array}{l}\text { Asia / Thailand } \\
\text { / Nonthaburi }\end{array}$ & $2020-01-05$ & EPI_ISL_434692 \\
\hline V70del & $\begin{array}{c}\text { BA.1, BA.3, and } \\
\text { BA.1.1 }\end{array}$ & Alpha, Eta 37 & $\begin{array}{l}\text { Asia / Thailand } \\
\text { / Nonthaburi }\end{array}$ & $2020-01-05$ & EPI_ISL_434692 \\
\hline T95I & $\begin{array}{c}\text { BA.1, BA.3, and } \\
\text { BA.1.1 }\end{array}$ & $\begin{array}{c}\text { Many Delta } \\
\text { sublineages, Iota, } \\
\text { Mu 37, 38 }\end{array}$ & Asia / Lebanon & $2020-01-10$ & EPI_ISL_8311730 \\
\hline G142D & $\begin{array}{l}\text { BA.1, BA.2, } \\
\text { BA.3, and } \\
\text { BA.1.1 }\end{array}$ & Delta 36 & $\begin{array}{c}\text { Asia / Japan / } \\
\text { Kanto }\end{array}$ & $2020-02-25$ & EPI_ISL_479852 \\
\hline
\end{tabular}


bioRxiv preprint doi: https://doi.org/10.1101/2022.02.25.481941; this version posted February 26, 2022. The copyright holder for this preprint (which was not certified by peer review) is the author/funder. All rights reserved. No reuse allowed without permission.

\begin{tabular}{|c|c|c|c|c|c|}
\hline V143del & $\begin{array}{c}\text { BA.1, BA.3, and } \\
\text { BA.1.1 }\end{array}$ & Alpha, Eta 38 & $\begin{array}{c}\text { Asia / Japan / } \\
\text { Kanto }\end{array}$ & $2020-02-25$ & EPI_ISL_479852 \\
\hline Y144del & $\begin{array}{c}\text { BA.1, BA.3, and } \\
\text { BA.1.1 }\end{array}$ & $\begin{array}{l}\text { Alpha, Eta, Mu } \\
\text { (Y144S) 37. }\end{array}$ & $\begin{array}{c}\text { Europe / } \\
\text { Switzerland / } \\
\text { Aargau }\end{array}$ & $2020-01-05$ & EPI_ISL_896091.3 \\
\hline Y145del & $\begin{array}{c}\text { BA.1, BA.3, and } \\
\text { BA.1.1 }\end{array}$ & $\begin{array}{l}\text { Alpha, Eta, Mu } \\
(\mathrm{Y} 145 \mathrm{~N})[37,38\end{array}$ & $\begin{array}{l}\text { North America / } \\
\text { USA / Virginia }\end{array}$ & $2020-03-30$ & EPI_ISL_429978 \\
\hline $\mathrm{N} 211 \mathrm{I}$ & $\begin{array}{c}\text { BA.1, BA.3, and } \\
\text { BA.1.1 }\end{array}$ & -- & $\begin{array}{c}\text { North America / } \\
\text { USA / Texas / } \\
\text { Houston }\end{array}$ & $2020-07-14$ & EPI_ISL_5343378 \\
\hline L212del & $\begin{array}{c}\text { BA.1, BA.3, and } \\
\text { BA.1.1 }\end{array}$ & - & $\begin{array}{c}\text { Europe / Spain / } \\
\text { Navarra }\end{array}$ & $2020-05-12$ & EPI_ISL_1382928 \\
\hline V213G & BA.2 & - & Asia / Iran & $2020-03-29$ & EPI_ISL_672575 \\
\hline ins214EPE & BA.1 and BA.1.1 & - & $\begin{array}{c}\text { Africa / Zambia } \\
\text { / Lusaka / } \\
\text { Lusaka }\end{array}$ & 2021-02-12 & EPI_ISL_7988145 \\
\hline \multicolumn{6}{|c|}{ Spike protein (RBD) } \\
\hline G339D & $\begin{array}{c}\text { BA.1, BA.2, } \\
\text { BA.3, and } \\
\text { BA.1.1 }\end{array}$ & - & $\begin{array}{l}\text { Europe / } \\
\text { Norway }\end{array}$ & $2020-03-05$ & EPI_ISL_420138 \\
\hline R346K & BA.1.1 & $\mathrm{Mu} 36$ & $\begin{array}{l}\text { North America / } \\
\text { Panama / Cocle }\end{array}$ & $2020-03-18$ & EPI_ISL_496747 \\
\hline S371L & BA.1 and BA.1.1 & - & $\begin{array}{l}\text { North America / } \\
\text { USA / Louisiana } \\
\text { / Lincoln Parish }\end{array}$ & $2020-12-27$ & EPI_ISL_8508546 \\
\hline $\mathrm{S} 371 \mathrm{~F}$ & BA. 2 and BA.3 & - & $\begin{array}{c}\text { Europe / Italy / } \\
\text { Campania }\end{array}$ & $2020-05-17$ & EPI_ISL_6832115 \\
\hline S373P & $\begin{array}{c}\text { BA.1, BA.2, } \\
\text { BA.3, and } \\
\text { BA.1.1 }\end{array}$ & - & $\begin{array}{c}\text { North America / } \\
\text { USA / Texas / } \\
\text { Houston }\end{array}$ & $2020-06-04$ & EPI_ISL_545554 \\
\hline S375F & $\begin{array}{c}\text { BA.1, BA.2, } \\
\text { BA.3, and } \\
\text { BA.1.1 }\end{array}$ & - & $\begin{array}{c}\text { Africa / Egypt / } \\
\text { Cairo }\end{array}$ & $2020-06-08$ & EPI_ISL_1097025 \\
\hline T376A & BA.2 & - & $\begin{array}{c}\text { Asia / Japan / } \\
\text { Saitama }\end{array}$ & 2021-06-09 & EPI_ISL_3198900 \\
\hline $\mathrm{D} 405 \mathrm{~N}$ & BA.2 and BA.3 & - & $\begin{array}{l}\text { Europe / } \\
\text { Portugal }\end{array}$ & 2021-02-09 & EPI_ISL_1116795 \\
\hline $\mathrm{R} 408 \mathrm{~S}$ & BA.2 & - & $\begin{array}{l}\text { Europe / } \\
\text { Netherlands / } \\
\text { Zuid-Holland }\end{array}$ & $2020-03-27$ & EPI_ISL_422951 \\
\hline $\mathrm{K} 417 \mathrm{~N}$ & $\begin{array}{c}\text { BA.1, BA.2, } \\
\text { BA.3, and } \\
\text { BA.1.1 }\end{array}$ & $\begin{array}{l}\text { Beta, Gamma } \\
(\mathrm{K} 417 \mathrm{~T}) \text {, two } \\
\text { sub lineages of } \\
\text { the Delta variant } \\
\text { (AY.1 and } \\
\text { AY.2) 38 }\end{array}$ & $\begin{array}{c}\text { Asia / Qatar / } \\
\text { Doha }\end{array}$ & $2020-03-27$ & EPI_ISL_2274264 \\
\hline \multicolumn{6}{|l|}{ RBD(RBM) } \\
\hline $\mathrm{N} 440 \mathrm{~K}$ & $\begin{array}{c}\text { BA.1, BA.2, } \\
\text { BA.3, and } \\
\text { BA.1.1 }\end{array}$ & - & $\begin{array}{c}\text { North America / } \\
\text { Canada / } \\
\text { Quebec }\end{array}$ & 2020-03-10 & EPI_ISL_3458197 \\
\hline
\end{tabular}


bioRxiv preprint doi: https://doi.org/10.1101/2022.02.25.481941; this version posted February 26, 2022. The copyright holder for this preprint (which was not certified by peer review) is the author/funder. All rights reserved. No reuse allowed without permission.

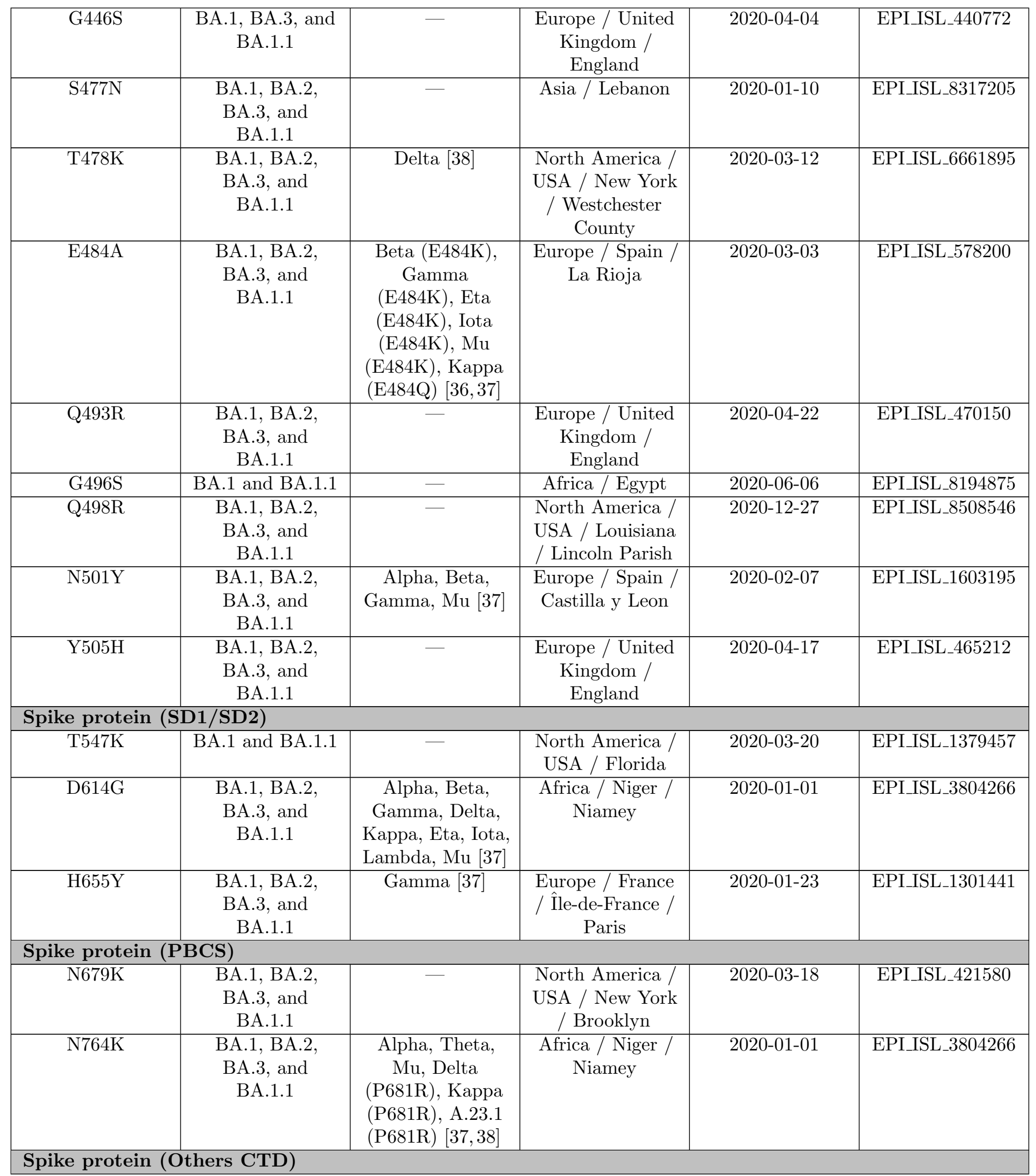


bioRxiv preprint doi: https://doi.org/10.1101/2022.02.25.481941; this version posted February 26, 2022. The copyright holder for this preprint (which was not certified by peer review) is the author/funder. All rights reserved. No reuse allowed without permission.

\begin{tabular}{|c|c|c|c|c|c|}
\hline N764K & $\begin{array}{c}\text { BA.1, BA.2, } \\
\text { BA.3, and } \\
\text { BA.1.1 }\end{array}$ & - & $\begin{array}{c}\text { Africa / Egypt / } \\
\text { Cairo }\end{array}$ & 2020-06-08 & EPI_ISL_1097025 \\
\hline D796Y & $\begin{array}{c}\text { BA.1, BA.2, } \\
\text { BA.3, and } \\
\text { BA.1.1 }\end{array}$ & - & $\begin{array}{c}\text { Europe / United } \\
\text { Kingdom / } \\
\text { Scotland }\end{array}$ & $2020-03-29$ & EPI_ISL_433364 \\
\hline N856K & BA.1 and BA.1.1 & - & $\begin{array}{l}\text { Asia / China / } \\
\text { Hubei / Wuhan }\end{array}$ & $2020-01-25$ & EPI_ISL_493156 \\
\hline Q954H & $\begin{array}{c}\text { BA.1, BA.2, } \\
\text { BA.3, and } \\
\text { BA.1.1 }\end{array}$ & - & $\begin{array}{c}\text { Africa / South } \\
\text { Africa / North } \\
\text { West }\end{array}$ & $2020-06-29$ & EPI_ISL_8182884 \\
\hline N969K & $\begin{array}{c}\text { BA.1, BA.2, } \\
\text { BA.3, and } \\
\text { BA.1.1 }\end{array}$ & - & $\begin{array}{l}\text { North America / } \\
\text { USA / Maryland }\end{array}$ & $2020-05-31$ & EPI_ISL_3098538 \\
\hline $\mathrm{L} 981 \mathrm{~F}$ & BA.1 and BA.1.1 & - & $\begin{array}{c}\text { North America / } \\
\text { USA / } \\
\text { Wisconsin / } \\
\text { Dane County }\end{array}$ & $2020-04-17$ & EPI_ISL_450716 \\
\hline \multicolumn{6}{|c|}{ ORF3a (NS3a) } \\
\hline $\mathrm{T} 223 \mathrm{I}$ & BA.2 and BA.3 & - & $\begin{array}{c}\text { Asia / India / } \\
\text { Himachal } \\
\text { Pradesh }\end{array}$ & $2020-02-24$ & EPI_ISL_2099688 \\
\hline \multicolumn{6}{|c|}{ E protein } \\
\hline T9I & $\begin{array}{c}\text { BA.1, BA.2, } \\
\text { BA.1.1, and } \\
\text { BA. } 3\end{array}$ & - & $\begin{array}{c}\text { North America / } \\
\text { USA / } \\
\text { Washington }\end{array}$ & $2020-03-12$ & EPI_ISL_476911 \\
\hline \multicolumn{6}{|l|}{ M protein } \\
\hline $\mathrm{D} 3 \mathrm{G}$ & BA.1 and BA.1.1 & - & $\begin{array}{c}\text { Asia / China / } \\
\text { Guangxi / } \\
\text { Nanning }\end{array}$ & $2020-02-19$ & EPI_ISL_6951243 \\
\hline Q19E & $\begin{array}{c}\text { BA.1, BA.2, } \\
\text { BA.1.1, and } \\
\text { BA.3 }\end{array}$ & - & $\begin{array}{c}\text { North America / } \\
\text { USA / New York } \\
\text { / Brooklyn }\end{array}$ & $2020-03-27$ & EPI_ISL_456032 \\
\hline $\mathrm{A} 63 \mathrm{~T}$ & $\begin{array}{c}\text { BA.1, BA.2, } \\
\text { BA.1.1, and } \\
\text { BA.3 }\end{array}$ & - & $\begin{array}{c}\text { Europe / United } \\
\text { Kingdom / } \\
\text { Scotland } \\
\end{array}$ & $2020-03-23$ & EPI_ISL_425915 \\
\hline \multicolumn{6}{|l|}{ ORF6 } \\
\hline $\mathrm{D} 61 \mathrm{~L}$ & BA.2 & - & $\mathrm{N} / \mathrm{A}$ & $\mathrm{N} / \mathrm{A}$ & $\mathrm{N} / \mathrm{A}$ \\
\hline \multicolumn{6}{|l|}{$\mathrm{N}$ protein } \\
\hline $\mathrm{P} 13 \mathrm{~L}$ & $\begin{array}{c}\text { BA.1, BA.2, } \\
\text { BA.1.1, and } \\
\text { BA.3 }\end{array}$ & Lambda 36 & $\begin{array}{c}\text { Oceania / Papua } \\
\text { New Guinea }\end{array}$ & $2020-01-13$ & EPI_ISL_1307662 \\
\hline E31del & $\begin{array}{l}\text { BA.1, BA.2, } \\
\text { BA.1.1, and } \\
\text { BA.3 }\end{array}$ & - & $\begin{array}{c}\text { Africa / Egypt / } \\
\text { Cairo }\end{array}$ & 2020-06-06 & EPI_ISL_1167190 \\
\hline R32del & $\begin{array}{c}\text { BA.1, BA.2, } \\
\text { BA.1.1, and } \\
\text { BA. } 3\end{array}$ & - & $\begin{array}{c}\text { Africa / Egypt / } \\
\text { Cairo }\end{array}$ & 2020-06-06 & EPI_ISL_1167190 \\
\hline S33del & $\begin{array}{l}\text { BA.1, BA.2, } \\
\text { BA.1.1, and } \\
\text { BA.3 }\end{array}$ & - & $\begin{array}{c}\text { Africa / Egypt / } \\
\text { Cairo }\end{array}$ & $2020-06-06$ & EPI_ISL_1167190 \\
\hline
\end{tabular}


bioRxiv preprint doi: https://doi.org/10.1101/2022.02.25.481941; this version posted February 26, 2022. The copyright holder for this preprint (which was not certified by peer review) is the author/funder. All rights reserved. No reuse allowed without permission.

\begin{tabular}{|c|c|c|c|c|c|}
\hline R203K & $\begin{array}{c}\text { BA.1, BA.2, } \\
\text { BA.1.1, and } \\
\text { BA.3 }\end{array}$ & $\begin{array}{c}\text { Alpha, Gamma, } \\
\text { Lambda 36] }\end{array}$ & $\begin{array}{c}\text { Oceania / } \\
\text { Australia / New } \\
\text { South Wales / } \\
\text { Sydney }\end{array}$ & 2020-01-08 & EPI_ISL_3568416 \\
\hline G204R & $\begin{array}{c}\text { BA.1, BA.2, } \\
\text { BA.1.1, and } \\
\text { BA.3 }\end{array}$ & $\begin{array}{c}\text { Alpha, Gamma, } \\
\text { Lambda 36] }\end{array}$ & $\begin{array}{c}\text { Oceania / } \\
\text { Australia / New } \\
\text { South Wales / } \\
\text { Sydney }\end{array}$ & $2020-01-08$ & EPI_ISL_3568416 \\
\hline S413R & BA.2 and BA.3 & - & Africa / Egypt & 2020-06-24 & EPI_ISL_2380075 \\
\hline
\end{tabular}

\section{The occurrence of mutation clusters in the previous variants}

To see if any mutations appear together in earlier variants we built a Sankey diagram based on the data in Table 1, as shown in Fig 2. We found that all mutations specific to the BA.2 lineage are unique to the Omicron variant. However, mutations specific to BA.1 variant as well as mutations shared between BA.1 and BA.2 have been found in several variants. The BA.1.1 and BA.3 lineages was excluded as BA.1.1 is identical to BA.1 in all mutations except for one mutation that it shares with the $\mathrm{Mu}$ variant, and all BA.3 mutations are shared with other lineages.

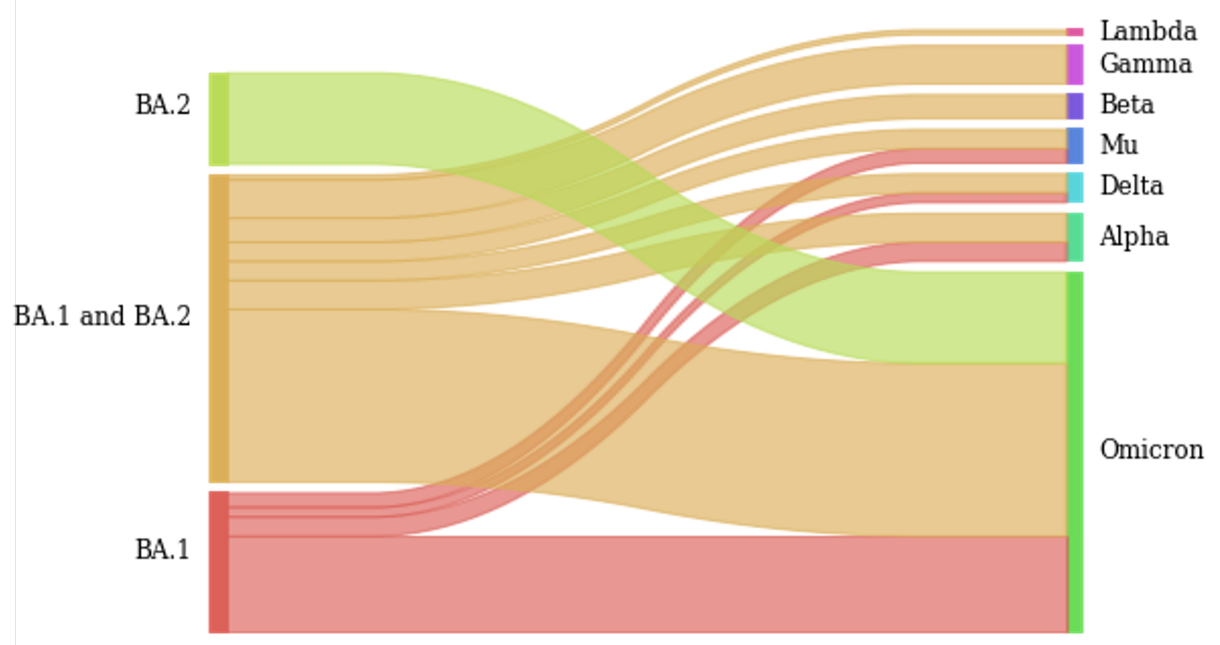

Fig 2. Sankey diagram. This diagram illustrates relationships between different Omicron lineages and variants graphically. The bars on the left show the lineages and the bars on the right represent the variants. The lines between the bars are reflecting the occurrence of mutations. The wider the connection lines are, the more appearance of mutations exists.

\section{Analysis of the Omicron's deletions sites for non dele- tion mutations in other variants}

Concerning non-Spike and Spike deletions in Omicron lineages, no other types of mutations were detected in earlier VOCs/VOIs at the same deletion sites, except for PPA25 
deletion mutation. In the Spike protein, the P26S substitution mutation has been identified in the Gamma variant, which occurs in the deletion site (25-27del) of the Omicron variant (BA.2 lineage). This substitution also occurs near the NTD supersite at residue with high antibody accessibility scores 39. This mutation has been linked with reduced binding with monoclonal sera [40].

\section{Detailed description of each mutation based on pub- lished data}

\section{Mutations in Spike protein}

The Spike protein is heavily mutated in the Omicron lineages BA.1, BA.2, BA.3, and BA.1.1 compared to other VOCs and VOIs (Fig 3). There are 21 mutations common in all of these four lineages. Comparing BA.1 and its sub-lineage BA.1.1, Spike protein revealed one additional mutation in BA.1.1 (R346K). There are 37 mutations in the Spike protein of BA.1, 31 mutations in the Spike protein of BA.2, 33 mutations in the Spike protein of BA.3, and 38 mutations in the Spike protein of BA.1.1. Comparing BA.1 and BA.2 lineages, Spike protein revealed 16 specific mutations in BA.1 lineage and 10 specific mutations in BA.2. BA.3 shares 10 mutations from BA.1-specific mutations and 2 mutations from BA.2-specific mutations to form its spike protein.

\subsection{Mutations in RBD}

Mutations in RBD may have a high impact on coronavirus fitness, as this region interacts with hACE2 receptors on human cells. Moreover a combination of few mutations may lead to cumulative effect. For instance,Nelson G et al.showed increased affinity for the ACE2 protein in presence of a combination of K417N, E484K and N501Y mutations, as they significantly affect RBD conformation 41. But in the case of the Omicron, there is E484A substitution for which it showed the ability to escape neutralising antibodies [42]. Same results were observed for a combination of S477N, E484K and N501Y mutations [43]. Below each mutation is discussed in further detail.

\subsubsection{G339D [BA.1, BA.1.1, BA.2, BA.3]}

This mutation might decrease binding affinity to ACE2 44].

\subsubsection{R346K [BA.1.1]}

Evaluation of the free energy perturbation (FEP) has shown that the effect of this mutation on antibody binding may not be significant, and it only affects class $2 \mathrm{mAbs}$. However, in the presence of other mutations (e.g. K417N), the neutralising activity of the antibodies may be reduced more significantly [45]. R346K is also found in the $\mathrm{Mu}$ variant of interest that emerged in early 2021.

\subsubsection{S371F [BA.2, BA.3]}

Previous mutation variants found in this position include S371P, S371F, S371T and S371A 46]. The S371 residue is located in one of the cryptic binding epitopes that are aligned with conserved hinge positions. In addition, the S371-F541 region shows a lack of glycosylated sites. Identification of such regions is necessary to search for potential epitopes for neutralising antibodies [47]. On the other hand, changes in the amino acid residue at the $\mathrm{S} 371$ position result in reduced $\mathrm{RBD}$ recognition by antibodies [48. For 
A.

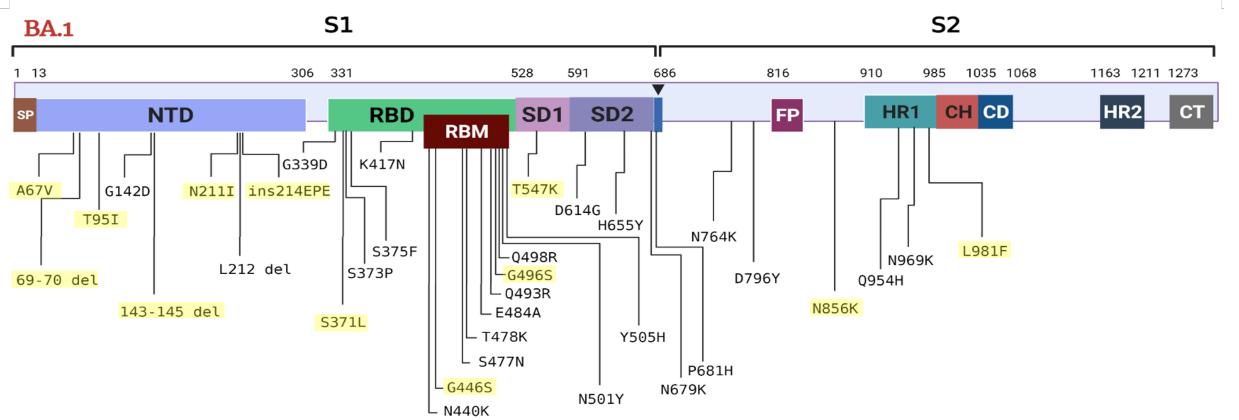

B.

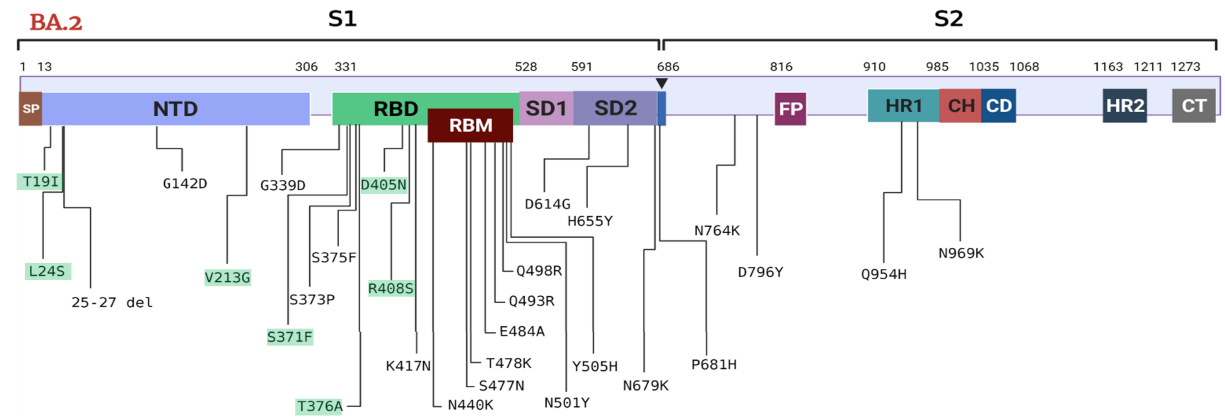

C.

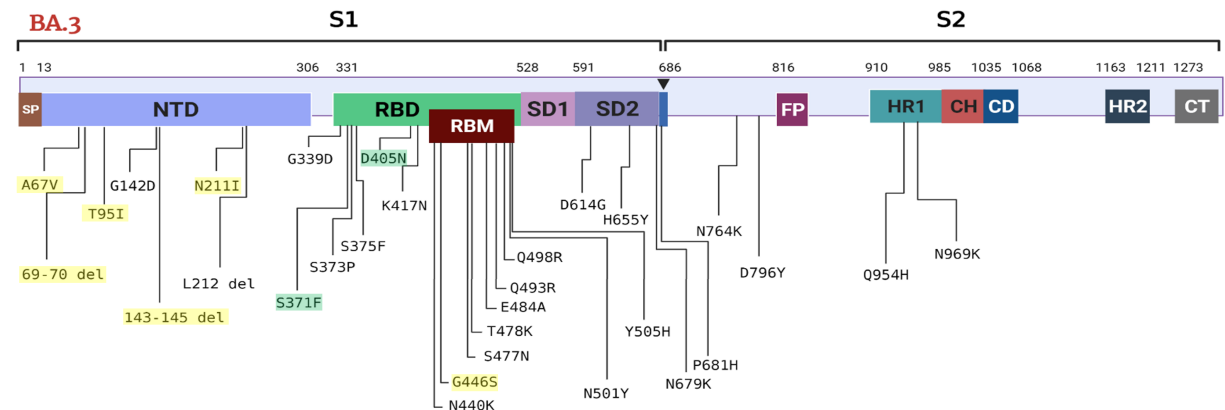

D.

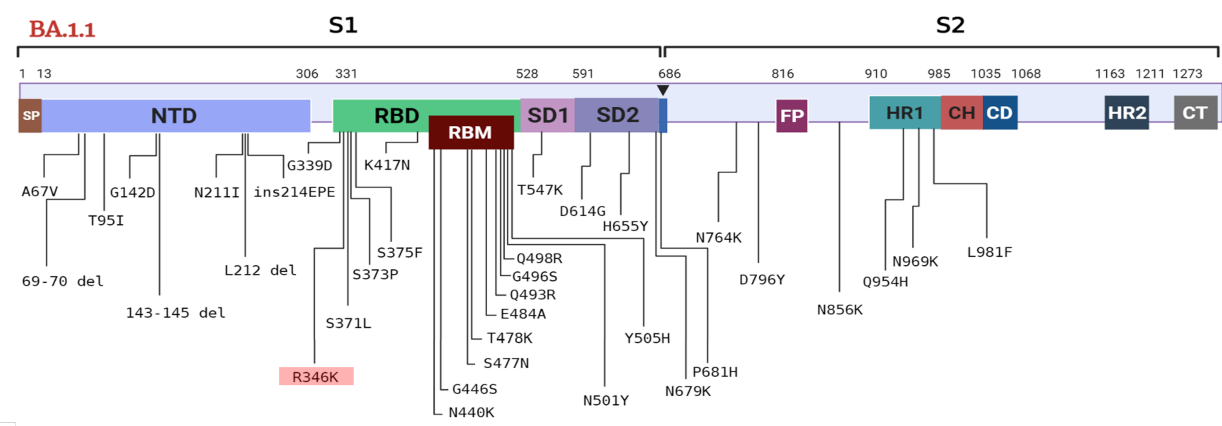

Fig 3. Schematic representation of the Spike protein mutations identified in the genome of the Omicron BA.1, BA.2, and BA.3 lineages, and BA.1.1 sub-lineage. Unique mutations are highlighted in yellow for BA.1 (A), in green for BA.2 (B) and in red for BA.1.1 (D). For BA.3 mutations shared with BA.1 are highlighted in yellow and mutations shared with BA.2 are highlighted in green (C). The Spike protein is composed of two subunits, S1 and S2. Arrow indicates the $\mathrm{S} 1 / \mathrm{S} 2$ protease cleavage site. Different domains are shown by different colors. SP: signal peptide; NTD: N-terminal domain; RBD: receptor-binding domain; RBM: receptor-binding motif; SD1: subdomain 1; SD2: subdomain 2; FP: fusion peptide; HR1: heptad repeat 1; CH: central helix; CD: connector domain; HR2: heptad repeat 2; CT, cytoplasmic tail. Created with BioRender 23]. 
example, a single S371L mutation (which occurs in BA.1) at this position results in avoidance of some neutralising antibodies (by changing the conformation). Possibly, the $\mathrm{S} 371 \mathrm{~F}$ mutation leads to a similar effect [49,50].

\subsubsection{S371L [BA.1, BA.1.1]}

This mutation decreases stability of the RBD and may reduce the ability of antibodies to recognise the Spike protein epitope [49.51.

\subsubsection{S373P [BA.1, BA.1.1, BA.2, BA.3]}

This mutation may help to escape neutralising antibodies 52 .

\subsubsection{S375F [BA.1, BA.1.1, BA.2, BA.3]}

This mutation probably first occurred in the Omicron. As it has effects on replacement of serin for phenylalanine, it may slightly change RBD conformation.

\subsubsection{T376A [BA.2]}

The T376 residue is located in the 2-strand, which may be an epitope for neutralising antibodies [53]. This mutation may be involved in evading recognition by neutralising antibodies, similar to other mutations in RBD [49].

\subsubsection{D405N [BA.2, BA.3]}

The D504N/Y mutation results in the escape of one of the monoclonal antibody groups that bind to the RBD base [54]. An important feature of this mutation is that it is located close to RBM, specifically the G504 residue. Hence can affect the RBM conformation 55]. In addition, residue D405 is involved in the Spike protein transition to the open form 56 .

\section{1 .9 R408S [BA.2]}

The R408K mutation in this position has a similar effect to the D504N mutation in reducing epitope recognition in $\mathrm{RBD}$ by monoclonal antibodies 54 ].

R408 as well as D405 are involved in the RBD-opening transition [56]. Thus, the study of these residues is important to elucidate their role for viral entry into the cell and how mutations affect this ability.

\subsubsection{K417N [BA.1, BA.1.1, BA.2, BA.3]}

This mutation helps the virus to escape monoclonal antibodies [57. This mutation alone showed a slightly lower or similar affinity for ACE 2 as wild type 58.

\subsubsection{N440K [BA.1, BA.1.1, BA.2, BA.3]}

Based on binding-free energy change, this mutation potentially might increase binding affinity to ACE2 receptors 44 .

\subsubsection{G446S [BA.1, BA.1.1, BA.3]}

While reducing RBD stability it is increasing ACE2 binding affinity [59]. Might help to escape neutralising antibodies 60. 


\subsubsection{S477N [BA.1, BA.1.1, BA.2, BA.3]}

This mutation shows resistance to neutralising monoclonal antibodies and increased ACE2 binding [8, 61]. Hence this mutation provides stronger transmissibility. At the same time, this mutation showed potency to lower binding affinity [44].

\subsubsection{T478K [BA.1, BA.1.1, BA.2, BA.3]}

This mutation arose multiple times independently. Since it occurs with high frequency, it may positively affect ACE2 binding affinity 62 .

\subsubsection{E484A [BA.1, BA.1.1, BA.2, BA.3]}

This mutation abolished binding of some neutralising antibodies [42 63].

\subsubsection{Q493R [BA.1, BA.1.1, BA.2, BA.3]}

This substitution reduces protein's susceptibility to some monoclonal antibodies in neutralisation assay 64].

\subsubsection{G496S [BA.1, BA.1.1]}

G496 is one of the key residues that interact with ACE2. For substitutions G496W and G496Y showed the largest binding energy change among all RBD mutations 65. G496S substitution has the same effect of enhancing binding capacity [66.

\subsubsection{Q498R [BA.1, BA.1.1, BA.2, BA.3]}

In combination with N501Y increases affinity to ACE2 [43].

\subsubsection{N501Y [BA.1, BA.1.1, BA.2, BA.3]}

This mutation appeared multiple times independently. It may affect affinity resulting in increasing ACE2 binding [41. Key mutation in combination K417N + E484K + N501Y [57].

\subsubsection{Y505H [BA.1, BA.1.1, BA.2, BA.3]}

Chen et al. showed that Y505 residue is a potential hotspot and has a most likely substitution Y505H 61]. Nevertheless this mutation may lead to reducing ACE binding affinity [59].

\subsection{Mutations in other Spike protein regions 0.2.1 T19I [BA.2]}

Variants of mutations in this position for the first half year of the pandemics were T19P, T19I, T19S 67]. But the Delta variant already contained a T19R substitution, hence it is currently the most common 68. The T19 site is located in the NTD in a region with a very high mutation density. As the NTD is located close to the RBD, it can therefore be an epitope for antibodies 69,70 . Thus, it can be assumed that this high variability of this site is a mechanism of antibody recognition avoidance. 


\subsubsection{LPPA24S [BA.2]}

This mutation results in a nucleotide deletion at positions 21633-21641 (TACCCCCTG), which causes a replacement LPPA24S. It probably has the same effect as the previous mutation, consisting in the evasion of recognition by neutralising antibodies.

\subsubsection{A67V [BA.1, BA.1.1, BA.3]}

Substitution of Ala for Val results in forming of novel hydrophobic bonds with I100, F79 and A263 residues. Therefore it slightly changes conformation of 3-4 loops 69.

\subsection{4 del69-70 [BA.1, BA.1.1, BA.3]}

This mutation might allosterically change $\mathrm{S} 1$ conformation and be supportive for mutations in RBD [71,72]. These deletions are associated with increased virus replication and also involved in the evasion of neutralizing antibodies 30,73 .

\section{2 .5 T95I [BA.1, BA.1.1, BA.3]}

One of the most prevalent mutations in the Delta variant 74 . Protein modeling has shown that by altering the NTD 3D structure may enhance G142 mutation and hence increase viral load 75 .

\subsubsection{G142D [BA.1, BA.1.1, BA.2, BA.3] $+\Delta$ 143/145 [BA.1, BA.1.1, BA.3]}

Similar deletion (del141-144) was found in isolated culture on 70th day obtained from immunocompromised patient with cancer 76$]$. Because of the location of this deletion in the recurrent deletion region 2 (RDR2), it can affect the ability to escape neutralising antibodies [7].

\subsubsection{Y145D}

Spike protein with this mutation has shown ability to escape some neutralising antibodies [78.

\subsubsection{NL211I del [BA.1, BA.1.1, BA.3]}

This mutation locates in the recurrent deletion region 3 (RDR3) and may affect ability to escape some neutralising antibodies 77 .

\subsubsection{V213G [BA.2]}

This mutation locates in the NTD of the Spike protein. No significant effects have been shown for it.

\subsubsection{0 ins214EPE [BA.1, BA.1.1]}

$86.3 \%$ of the Omicron variant samples contain this insertion (nucleotides GAGCCAGAA) 79. Like other alternative insertions in this site, it may affect SARS-CoV-2 infectivity as located next to RDR3 [80].

\subsubsection{T547K [BA.1, BA.1.1]}

Cases of this mutation were already registered [52, but it was first fixed in the Omicron. 


\subsubsection{D614G [BA.1, BA.1.1, BA.2, BA.3]}

In March of 2020, this mutation first occurred, and very fast became prevalent in most samples. Facilitate proteolysis in furin cleavage site and hence may increase transmissibility [81.

\subsubsection{H655Y [BA.1, BA.1.1, BA.2, BA.3]}

Braun, K. et al. suggested that this mutation might be under positive selection in domestic cats. Associated with furin cleavage site 82 .

\subsubsection{N679K and P681H [BA.1, BA.1.1, BA.2, BA.3]}

Both these mutations are located in the region of S1/S2 junction. Changing from neutral charged amino acids to the positive charged residues results in enhancing of coupling furin cleavage site with proteolytic enzyme hence that leads to increasing cleavability of spike S1/S2 site 83. But at the same time, for a single N679K substitution, it is shown that it alone is not enough to increase transmissibility [84].

\subsubsection{N764K [BA.1, BA.1.1, BA.2, BA.3]}

This mutation first fixed in the Omicron. It might decrease protein stability and reduce its function [51].

\subsubsection{D796Y [BA.1, BA.1.1, BA.2, BA.3]}

Appeared a few times independently 30,85 , including a case of intra-host evolution in a immunocompromised (HIV) patient [27].

\subsubsection{N856K [BA.1, BA.1.1]}

Located between fusion peptide (FP) and heptad repeat 1 (HR1) regions of Spike protein 86 . The mutation consists of a substitution with a positively charged amino acid, which can locally affect the conformation of this region and increase the affinity to certain proteins.

\subsubsection{Q954H, N969K [BA.1, BA.1.1, BA.2, BA.3] and L981F [BA.1, BA.1.1]}

These mutations are located within the heptad repeat 1 (HR1) region that acts in the process of fusion with the host cell. Thus these mutations may affect transmissibility and infectivity 86,87 .

\section{$1 \quad$ Non-Spike mutations}

Non-Spike regions are remarkably mutated in the Omicron lineages BA.1, BA.2, BA.3, and BA.1.1 compared to other VOCs and VOIs (Fig 4). There are 16 non-Spike mutations common in all of these four lineages. Comparing BA.1 and its sub-lineage BA.1.1, revealed that there is no additional mutations in the non-Spike proteins of BA.1.1. Comparing BA.1 and BA.2 lineages, there are 6 specific mutations in BA.1 lineage and 11 specific mutations in BA.2. BA.3 shares 5 mutations from BA.2-specific mutations and has one specific mutation (NSP6:A88V). 
A.

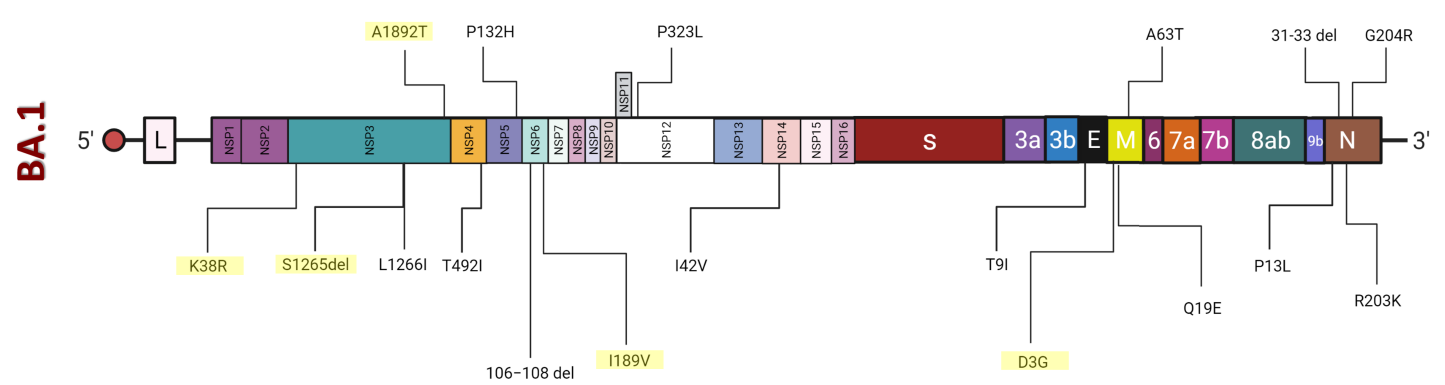

B.

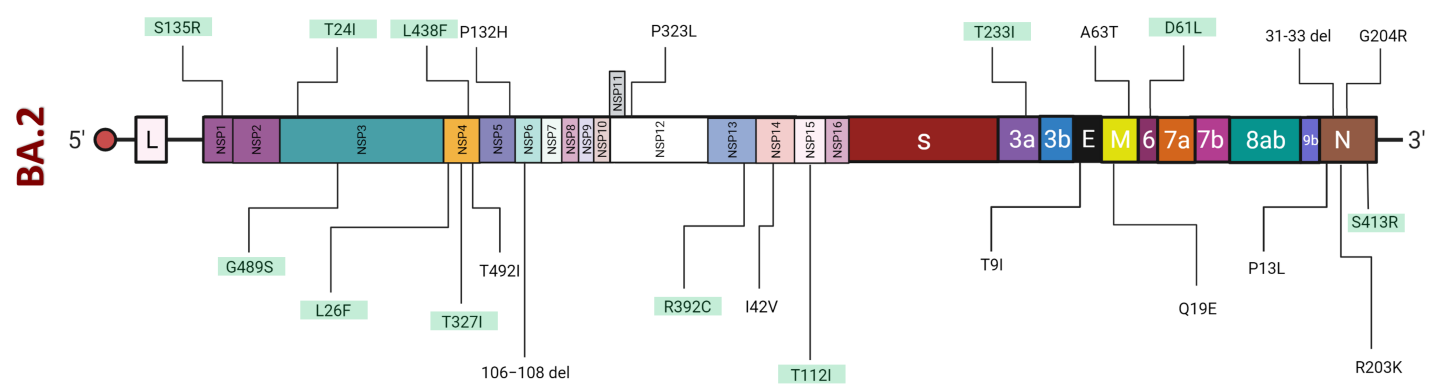

C.

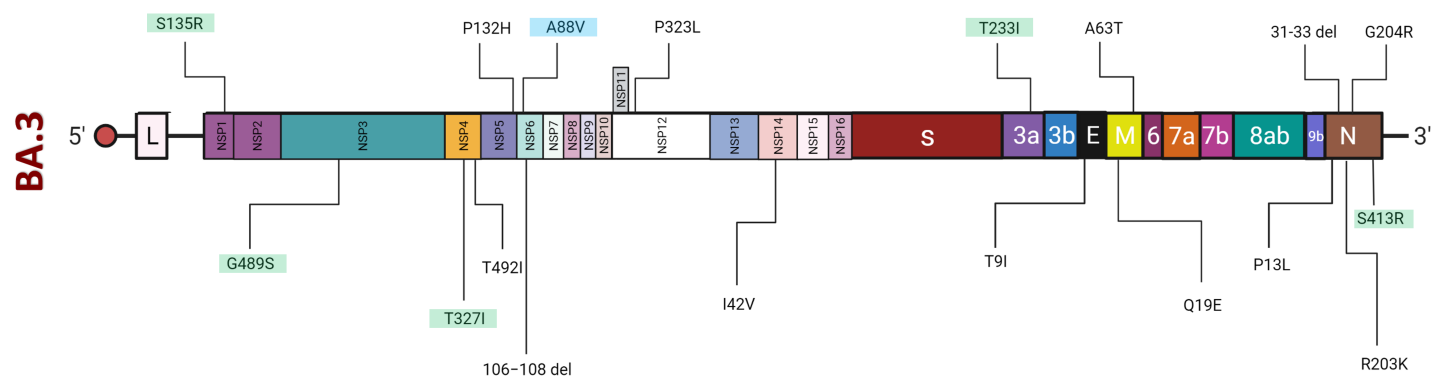

D.

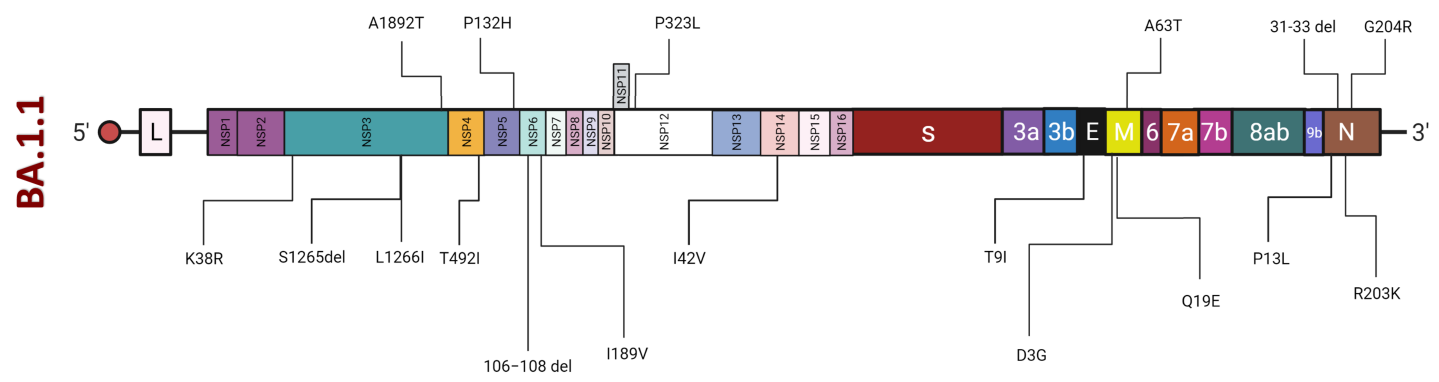

Fig 4. Schematic representation of the non-Spike mutations identified in the genomes of the Omicron BA.1, BA.2 and BA.3 lineages, and BA.1.1 sub-lineage. Unique mutations are highlighted in yellow for BA.1 (A), in green for BA.2 (B) and in blue for BA.3 (C). Mutations shared between BA.2 and BA.3 are highlighted in green (C). There are 22 mutations outside the Spike protein of BA.1, 27 mutations outside the Spike protein of BA.2, 22 mutations outside the Spike protein of BA.3, and 22 mutations outside the Spike protein of BA.1.1. Created with BioRender 23.

\subsection{Mutations in $\mathrm{E}$ protein}

\subsubsection{T9I [BA.1, BA.1.1, BA.2, BA.3]}

Located in the transmembrane domain, this mutation can affect the configuration of $\mathrm{E}$ protein and provides a stronger anchoring to the viral membrane 88, 89. 


\subsection{Mutations in $\mathrm{M}$ protein}

\subsubsection{D3G [BA.1, BA.1.1]}

One of the most frequent mutations in M protein [90]. Locates in the exposed NTD region, mutation in which may affect the interactions with host cells 91].

\subsubsection{Q19E and A63T [BA.1, BA.1.1, BA.2, BA.3]}

There is no data on effects of these mutations yet.

\subsection{Mutations in $\mathrm{N}$ protein}

\subsubsection{P13L [BA.1, BA.1.1, BA.2, BA.3]}

Oulas, A. et al. suggested that this mutation is associated with lower levels of transmissibility and death rates 92 .

\subsection{2 $\Delta$ 31-33 [BA.1, BA.1.1, BA.2, BA.3]}

Deletion consists in the substitution of "GERS" for "G". Located near the N-terminal domain, thus can affect the assembly with $\mathrm{M}$ protein 93 .

\subsubsection{R203K and G204R [BA.1, BA.1.1, BA.2, BA.3]}

R203K and G204R mutations in nucleocapsid have been shown to be linked to increased subgenomic RNA expression 94 and increased viral loads 95. In addition, these mutations are found in patients with inferior outcomes 96 .

\subsubsection{S413R [BA.2, BA.3]}

$\mathrm{N}$ protein is highly phosphorylated and enriched with basic residues. Basic residues properties help to form a sustainable complex with viral RNA, while the role of phosphorylation is not defined. However, for phosphorylation null mutants viral particles have been shown to be assembled with comparable or slightly lower efficiency than the wild type [97. Therefore, the loss of phosphorylation at some sites might negatively affect the process of packaging RNA into the nucleocapsid envelope. Residue S413 is one of the phosphorylation sites. From one side mutation S413R changes polar uncharged Serine for basic charged Arginine, on another side it removes phosphorylation from Serine. Hence it is unclear whether the S413R mutation has a positive effect on viral particle assembly (change to the major residue) or a negative effect (it eliminates phosphorylation).

\subsection{Mutations in NSP1 (leader protein)}

\subsubsection{S135R [BA.2, BA.3]}

Hydrogen-bond interaction analysis showed that S135 residue in NSP1 forms hydrogen bonds with C16 and C20 nucleotides of SARS-CoV-2 5'-UTR stem loop 98. Substitution of Serine for Arginine may increase RNA compatibility and as result enhance recognition.

\subsection{Mutations in NSP3}

\subsubsection{T24I (ORF1ab: T842I) [BA.2]}

This mutation first fixed in B.1.1.529. No significant effects have been reported for it, yet. It locates in the ubiquitin-like domain 199 . 


\subsubsection{K38R (ORF1ab: K856R) [BA.1, BA.1.1]}

Locates in the ubiquitin-like domain 1 [99].

\subsubsection{G489S (ORF1ab: G1307S) [BA.2, BA.3]}

No effects have been reported for this mutation yet.

\subsubsection{5 + L1266I (ORF1ab: SL2083I) [BA.1, BA.1.1]}

No effects have been reported for these mutations yet.

\subsubsection{A1892T (ORF1ab: A2710T) [BA.1, BA.1.1]}

No significant effects have been reported for this mutation yet.

\subsection{Mutations in NSP4}

\subsubsection{L264F (ORF1ab: L3027F) [BA.2]}

This mutation may have appeared several times independently in different lines 100 101].

\subsubsection{T327I (ORF1ab: T3090I) [BA.2]}

This mutation was detected in some samples early in the pandemic 102,103, but has not become widespread since then.

\subsubsection{L438F (ORF1ab: L3201F) [BA.2]}

L438F mutation was detected several times before, but has not become widespread 104.

\subsubsection{T492I (ORF1ab: T3255I) [BA.1, BA.1.1, BA.2, BA.3]}

One of the most frequently co-occurring with S:T478K non-spike mutation 62.

\subsection{Mutations in NSP5}

\subsubsection{P132H (ORF1ab: P3395H) [BA.1, BA.1.1, BA.2, BA.3]}

No significant effects have been noted for this mutation. The crystal structure shows that it is located away from the active centre and both alternative binding regions 105.

\subsection{Mutations in NSP6}

\subsubsection{A88V (ORF1ab: A3657V) [BA.3]}

No effects have been reported for this mutation yet.

\subsubsection{L105F (ORF1ab:L3674F) [BA.1, BA.1.1, BA.2] + $\Delta$ 105-107 (ORF1ab: SGF3675del) [BA.1, BA.1.1, BA.2, BA.3]}

This deletion results in the replacement of amino acids 'SLSG' by 'S' (Serine). This Serine is directly followed by Phenylalanine, for which it has been shown to increase the affinity of NSP6 to the endoplasmic reticulum membrane. It is suggested that this binding helps to avoid the delivery of viral particles to the lysosomes. Hence, this deletion may be part of the mechanism of innate immunity evasion 106,107. 


\subsubsection{F108L (ORF1ab: F3677L) [BA.2]}

Is more likely to occur in P.1 (18.2\%) [108, but globally the deletion (NSP6:S106/G107/F108del) is more common in this position. According to GISAID (as on 1 September 2021), this deletion is found in $97.21 \%$ of the sequences [109.

\subsubsection{I189V (Orf1ab: I3758V) [BA.1, BA.1.1]}

Sun et al. suggested that this mutation may affect viral shedding and hence transmissibility, thereby altering viral load [110]. Although this assumption requires experimental verification.

\subsection{Mutations in NSP12}

\subsubsection{P323L (ORF1ab: P4715L) [BA.1, BA.1.1, BA.2, BA.3]}

At least in Turkey this mutation has been found in a large number of samples [11] and presumably in combination with D614G mutation in the spike protein may have a correlation with severity of the disease $[112$.

\subsection{Mutations in NSP13}

\subsubsection{R392C (ORF1ab: R5716C) [BA.2]}

Sengupta et al. analysed the effects of different mutations on the properties and functions of coronavirus proteins. PROVEAN (Protein Variation Effect Analyzer) score showed that R392C mutation have deleterious effects on NSP13 protein and Gibbs free energy $(\Delta \Delta \mathrm{G})$ measured -1.29 [113. In addition, this mutation results in the substitution of a positively charged amino acid for a polar uncharged residue. Thus, this mutation may lead to a slight change in protein folding. The 114] study also suggests the ability of this mutation to alter the secondary structure of the protein.

In humans, the $\mathrm{R} 392 \mathrm{C}$ mutation is less frequent $(<0.5 \%$ of human isolates) and is more common in the mink population (10.5\% of mink isolates) 115 .

\subsection{Mutations in NSP14}

\subsubsection{I42V (ORF1ab: I5967V) [BA.1, BA.1.1, BA.2, BA.3]}

The I42V mutation is not expected to have a significant effect on the protein structure as it consists of the substitution of one hydrophobic amino acid (Isoleucine) for another hydrophobic amino acid (Valine).

\subsection{Mutations in NSP15}

\subsubsection{T112I (ORF1ab: T6564I) [BA.2]}

No effects have been reported for this mutation yet.

\subsection{Mutations in ORF3a}

\subsubsection{T223I [BA.2, BA.3]}

Located in the cytosolic domain near the hydrophobic core. Replacing the polar uncharged amino acid (Threonine) with a hydrophobic amino acid (Isoleucine) can slightly change the protein conformation 116. 


\subsection{Mutations in ORF6}

\subsubsection{D61L [BA.2]}

The D61L mutation results in the substitution of a negatively charged residue (Aspartic acid) with a hydrophobic residue (Leucine). This substitution can lead to the formation of a stronger ORF6:IRF3 complex. This in turn leads to an increase in the antagonistic properties of ORF6 against IFN 88 .

\section{Spike mutations aren't the only ones that matter}

\section{Mutations in NSP1 are important}

NSP1 (or leader protein) interacts with 40S subunit of the ribosome, inhibits host gene expression, and also evades the immune system. Furthermore, NSP1 degrades host mRNA and facilitates viral gene expression 117,118 . Leader protein contains a globular region that recognize the stem loop of the 5'-UTR region of SARS-CoV-2 RNAs hence viral genes continue to translate 98 .

This protein has been proposed as a target for vaccine development and also for drug design. The majority of mutations occuring in NSP1 exhibited a destabilizing effect and increased flexibility [119.

\section{Mutations in NSP3 are important}

NSP3 has been proposed to work with nsp4 and nsp6 to induce double-membrane vesicles (DMVs), which serve as an important component of the replication/transcription complex (RTCs) 120. Moreover NSP3 interacts with the N-terminal domain of the nucleocapsid phosphoprotein $(\mathrm{N})$, which leads to binding of the nucleocapsid and RTCs [121]. NSP3 also antagonists type I interferon mediated immune response, and blocks NF-kappasignal transduction 122 123. Mutations in NSP3 had been linked with positive selection of viruses leading to evolution in beta-coronaviruses 124 .

\section{Mutations in NSP4 are important}

NSP4 participates in assembly of cytoplasmic DMVs and helps in viral replication 120 , 125 .

\section{Mutations in NSP5 are important}

NSP5 or main protease (Mpro), also known as 3C-like protease (3CLpro) is essential for viral life cycle as it cleaves polyproteins pplab and ppla into distinct functional proteins 126. Therefore, this protein is a putative target for anticoronavirus therapy. NSP5 may be involved in evading the innate immune response by inhibiting mitochondrial antiviral signalling (MAVS) protein and IFN induction [127. Mutations in this protein can affect its proteolytic activity.

\section{Mutations in NSP6 are important}

Along with NSP3 and NSP4 is involved in the assembly of DMVs, which contain replication/transcription complexes. Furthermore, NSP6 has also been shown to have affinity to endoplasmic reticulum, which is provided by phenylalanine residues in the sequence of this protein 106 .

Deletion mutation in NSP6 from 105-107 could aid in innate immune evasion, possibly by compromising cells' ability to degrade viral components [106]. 


\section{Mutations in NSP12 (RNA-dependent RNA polymerase) are important}

Variants of RNA-dependent RNA polymerase (RdRp) emerged early during the COVID19 outbreak in China, North America, Europe, and Asian countries and hence RdRp was considered as a mutation hotspot 128, 129. The RdRp:P323L mutation was found to be associated with increasing point mutations in viral isolates in Europe during the early phase of COVID-19 outbreak [130. Thus, it is possible that mutations in RdRp might alter the interaction of RdRp with the cofactors which could yield less effective proofreading activity leading to the emergence of multiple SARS-CoV-2 variants 128 . In silico analysis predicted the docking site of antiviral drugs within a hydrophobic cleft located near the RdRp:P323L mutation site. This mutation was predicted to diminish the affinity of RdRp for existing antiviral drugs [128].

\section{Mutations in NSP13 are important}

NSP13 has several essential functions, including: (1) helicase activity in the 5'->3' direction, (2) the ability to unwind RNA/DNA duplex, (3) 5'm-RNA capping activity. Mutations in the active sites of this protein can affect the metabolism of the virus 126 , 131 .

\section{Mutations in NSP14 are important}

NSP14 acts as a 3'-5' exoribonuclease (N-terminal domain) for RNA replication proofreading. In addition, this protein has a second function acting as an N7-methyltransferase (C-terminal domain). Consequently, mutations in this protein may affect the proofreading of newly synthesised viral mRNAs or their stability 132 . Potentially can inhibit interferon signalling 133 .

\section{Mutations in NSP15 are important}

NSP15 is an endoribonuclease that cleaves the 3'-end of uridylates 134 . This functionality allows coronaviruses to avoid an innate immune response by cleaving the 5'-polyuridines of the viral RNA, and hence preventing the activation of dsRNA sensors [126, 135.

NSP15 is an essential protein for the viral life cycle, as it has been shown that mutations in this protein can lead to a rapid antiviral response in macrophages, thereby suppressing infection in a short period of time 135.

\section{Mutations in ORF3a are important}

Forms the ion channel. Initiates the lysis process of the host cells to allow new viral particles shedding. Also involved in the autophagy inhibition and disruption of lysosomes. Therefore, it is an essential protein for the viral cycle 116 131].

Because ORF3a is located on the surface of the membrane, it is able to induce a cellular and humoral immune response in infected individuals 136 .

\section{Mutations in $M$ protein are important}

Most conserved protein and most abundant structural protein. Have ability to interact with N, S proteins and viral RNA [90. Mutations occurring in the M protein could influence the host cell interaction 137. 


\section{Mutations in E protein are important}

The mutations found in the E protein may change the structural conformation of this protein and subsequently alter the associated functions such as viral assembly, replication, propagation, and pathogenesis as also previously observed in SARS-CoV 138,139.

\section{Mutations in ORF6 are important}

It has been shown that ORF6 can act as a suppressor of interferon signalling by inhibiting primary interferon production. ORF6 can therefore interfere in the induction of innate immune response. Molecular docking and dynamics simulation analysis showed that the C-terminal region of the ORF6 protein is able to interact with the transcription factor IRF3 via hydrophobic bonds. Thus, ORF6 acts as an IFN antagonist 88].

\section{Mutations in $\mathbf{N}$ protein are important}

Nucleocapsid phosphoprotein interacts with $\mathrm{M}$ protein during viral assembling. Has N-terminal and C-terminal domains that can bind RNA. All SARS-CoV-2 variants of interest or concern defined by the WHO contain at least one mutation with $>50 \%$ penetrance within seven amino acids (N:199-205) in the nucleocapsid (N) protein, indicating significance of this region 36,140 .

\section{D Spike Model for Omicron lineages}

The 3D structure of reference SARS-CoV-2 spike glycoprotein (closed state) is available in Protein Data Bank (PDB) with PDB ID: 6VXX. Similarly, the reference spike protein domain bound with ACE2 is obtainable with ID 6M0J. The crystalline cryo-EM structure of the Omicron lineage BA.1 spike protein (ID:7T9J) in complex with human ACE2 (ID:7T9K) had been added. However, the crystalline structure of spike protein for BA.1.1, BA.2, and BA.3 are not available.

Although, Parvez S. et al. build a 3D model of spike RBD of SARS-CoV-2 Omicron variant using SWISS-MODEL homology modelling [141] and wild-type spike protein (PDB ID 6M1) as a template. Their model is of good quality and highly reliable. Their validation analysis showed that overall quality factor of the model was $97.591 .8 \%$ residues were in the most favourable regions with $7.6 \%$ residues in highly allowed regions 142 . Kumar et al. have generated the structure of BA.1.1, BA.2, and BA.3 by homology modeling with the SWISS-MODEL server. The template PDB ID:7T9L is used to build the 3D structure, and the sequence identity for BA.1.1, BA.2, and BA.3 are $99.50 \%, 97.01 \%$, and $98.51 \%$, respectively. To evaluate the structure of homology models Ramachandran plot and Errat plot were used. Ramachandran plot of homology modeled RBD of BA.2 and BA.3 showed $90.2 \%$ residues in preferred areas and $9.8 \%$ residues in additional permitted regions while Errat score for both is 89.4 [21].

The molecular docking between RBD and ACE2 receptor shows that BA.1, BA.1.1, BA.2, and BA.3 have a greater affinity of binding compared to reference SARS-CoV-2 which might cause enhanced transmission of Omicron lineages. At the interface 19 residues of spike protein and 18 residues of ACE-2 protein interact with each other. On the RBD, among the 12 common mutations, 5 showed a higher binding affinity with hACE2, which was also affirmed by previous research conducted by Rehman et al. [143]. We created a 3D model of the spike RBD region using PyMOL software 144. We labeled only unique mutations for each lineage that are not shared between lineages (Fig 5). 

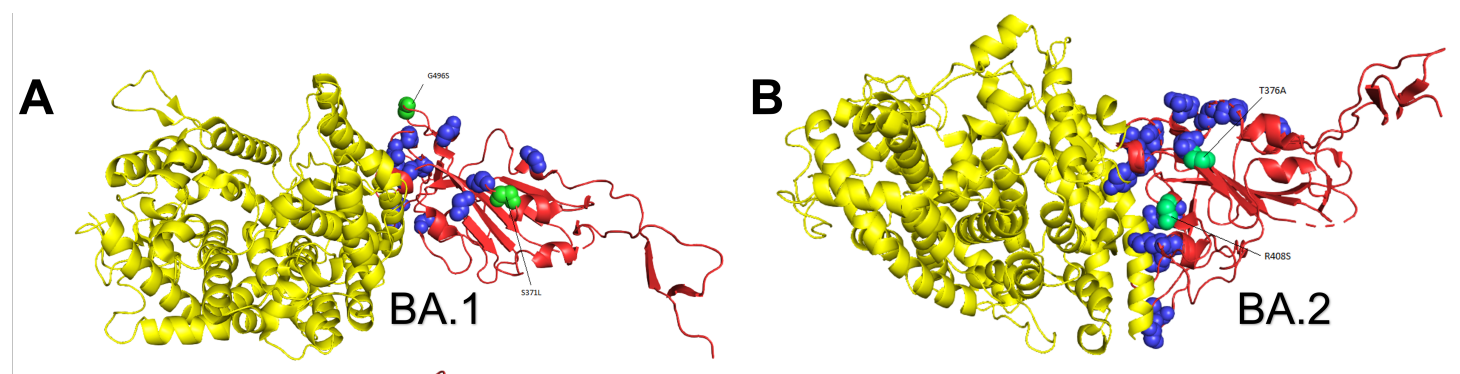

\section{C}

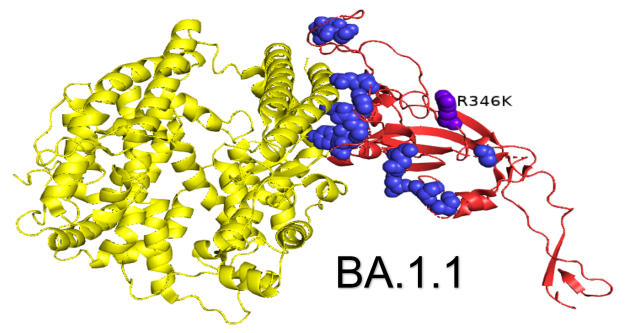

D

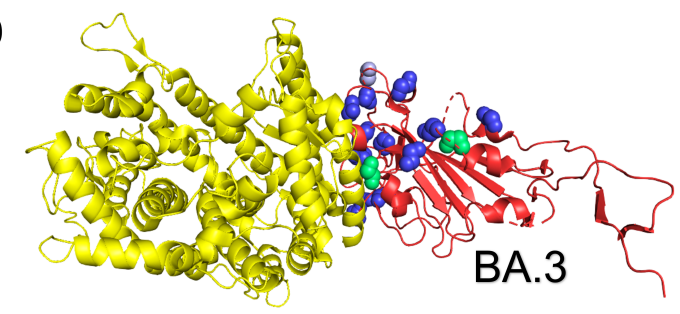

Fig 5. 3D modelling of spike RBD of SARS-CoV-2 Omicron lineages. ACE2 in yellow, RBD in red, Mutations shared between all lineages are in blue. Unique mutant residues in the RBD of BA.1 (A) and BA.2 (B) lineages are labeled. (C) The RBD structure of the BA.1.1 sub-lineage with its only one unique mutant residue. (D) The RBD structure of the BA.3 lineage with highlighted mutant residues, Light green: mutation shared between BA.2 and BA.3, Grey: mutation shared between BA.1 and BA.3. Created with PyMOL [144].

\section{Conclusion}

Virological characteristics of newly emerging SARS-CoV-2 variants, such as pathogenicity, transmissibility, resistance to antiviral drugs, and vaccine-induced immunity, are a critical global health concern. Omicron was first reported from South Africa at the end of November 2021. Then the Omicron lineages have rapidly spread worldwide and outcompeted other variants such as Delta. In this study, the mutational spectrum of Omicron lineages (BA.1, BA.1.1, BA.2, and BA.3) was explored in detail. We demonstrated where and when each of these mutations has been previously detected, which mutations were observed in the earlier variants, and how Omicron differs from them. Our study established that the Omicron variant has maintained several mutations that are found in other variants of concern and are thought to make the virus more infectious. We have also found that many of Omicron's mutations, are extremely rare in other SARS-CoV-2 variants, and represent a considerable jump in SARS-CoV-2 evolution. Accordingly, the mutation rate of the Omicron variant is exceeding the other variants. As well, it has enhanced transmissibility and immune evasion. This progression demonstrates the attempt of the Omicron variant to drive the SARS-CoV-2 for heightened viral fitness.

Based on the Omicron mutation profile in the non-spike regions, we have clarified that it might have collectively enhanced infectivity relative to previous SARS-CoV-2 variants. These mutations have shown to be directly/indirectly associated with the transmission advantages and immune escape. Accordingly, these mutations are worth more studies and investigation. Certainly, more-fit variations can be anticipated to develop over time, and then the occurrence of which has to be monitored thoroughly, as these pose a possible public health threat. The good news is that nothing is infinite, and, eventually, new variants will provide no further advantage in infectivity. 


\section{Supplementary materials}

\section{Supplementary Table 1. Detailed annotation of Omicron mutations. \\ Supplementary Table 2. Characteristics of VOCs and VOIs.}

Data availability Tables in different formats are available from Github repository: https://github.com/aglabx/omicronic.

\section{Acknowledgments}

We gratefully acknowledge the authors, originating and submitting laboratories where the clinical specimens and/or virus isolates were obtained and published through GISAID on which this research was based. We also thank the BioRender's authors for their library icons which helps with figure design.

\section{Funding}

Aleksey Komissarov was financially supported by the ITMO Fellowship and Professorship Program.

\section{References}

1. Hui KPY, Ho JCW, chun Cheung M, chun Ng K, Ching RHH, ling Lai K, et al. SARS-CoV-2 Omicron variant replication in human bronchus and lung ex vivo. Nature 2022. 2022; p. 1-5. doi:10.1038/s41586-022-04479-6.

2. Lu R, Zhao X, Li J, Niu P, Yang B, Wu H, et al. Genomic characterisation and epidemiology of 2019 novel coronavirus: implications for virus origins and receptor binding. The Lancet. 2020;395:565574. doi:10.1016/S0140-6736(20)30251-8/ATTACHMENT/1686D69B-3F2C44B2-A8A5-C648EF9D1C2B/MMC1.PDF.

3. Tracking SARS-CoV-2 variants;. Available from: https://www.who.int/en/ activities/tracking-SARS-CoV-2-variants/.

4. SARS-CoV-2 variants of concern as of 10 February 2022;. Available from: https://www.ecdc.europa.eu/en/covid-19/variants-concern.

5. Enhancing response to Omicron SARS-CoV-2 variant;. Available from: https://www.who.int/publications/ m/item/enhancing-readiness-for-omicron-(b.1.1.529)

-technical-brief-and-priority-actions-for-member-states.

6. SARS-CoV-2 Omicron variant cases worldwide 2022 - Statista; Available from: https://www.statista.com/statistics/1279100/ number-omicron-variant-worldwide-by-country/

7. Venkatakrishnan A, Anand P, Lenehan PJ, Suratekar R, Raghunathan B, Niesen MJM, et al. Omicron variant of SARS-CoV-2 harbors a unique insertion mutation of putative viral or human genomic origin;doi:10.31219/OSF.IO/F7TXY. 
8. Liu Z, VanBlargan LA, Bloyet LM, Rothlauf PW, Chen RE, Stumpf S, et al. Identification of SARS-CoV-2 spike mutations that attenuate monoclonal and serum antibody neutralization. Cell Host Microbe. 2021;29:477-488.e4. doi:10.1016/J.CHOM.2021.01.014.

9. Liu Y, Liu J, Plante KS, Plante JA, Xie X, Zhang X, et al. The N501Y spike substitution enhances SARS-CoV-2 infection and transmission. Nature 2021 602:7896. 2021;602:294-299. doi:10.1038/s41586-021-04245-0.

10. Jhun H, Park HY, Hisham Y, Song CS, Kim S. SARS-CoV-2 Delta (B.1.617.2) Variant: A Unique T478K Mutation in Receptor Binding Motif (RBM) of Spike Gene. Immune Network. 2021;21. doi:10.4110/IN.2021.21.E32.

11. Plante JA, Liu Y, Liu J, Xia H, Johnson BA, Lokugamage KG, et al. Spike mutation D614G alters SARS-CoV-2 fitness. Nature 2020 592:7852. 2020;592:116121. doi:10.1038/s41586-020-2895-3.

12. Wu L, Zhou L, Mo M, Liu T, Wu C, Gong C, et al. SARS-CoV-2 Omicron RBD shows weaker binding affinity than the currently dominant Delta variant to human ACE2. Signal Transduction and Targeted Therapy 2022 7:1. 2022;7:1-3. doi:10.1038/s41392-021-00863-2.

13. Mallapaty S. Where did Omicron come from? Three key theories. Nature. 2022;602:26-28. doi:10.1038/D41586-022-00215-2.

14. Sun C, Kang YF, Liu YT, Kong XW, Xu HQ, Xiong D, et al. Parallel profiling of antigenicity alteration and immune escape of SARS-CoV-2 Omicron and other variants. Signal Transduction and Targeted Therapy 2022 7:1. 2022;7:1-10. doi:10.1038/s41392-022-00910-6.

15. GISAID Initiative;. Available from: https://www.epicov.org/epi3/ frontend\#566d65.

16. Nextstrain / groups / blab / ncov / omicron;. Available from: https: //nextstrain.org/groups/blab/ncov/omicron?f_clade_membership=21K\% $20 \% 280$ micron $\% 29 \&$ transmissions=show.

17. Cov-Lineages;. Available from: https://cov-lineages.org/global_report_ B.1.1.529.html.

18. CoVariants;. Available from: https://covariants.org/variants/21K Omicron.

19. Suzuki R, Yamasoba D, Kimura I, Wang L, Kishimoto M, Ito J, et al. Attenuated fusogenicity and pathogenicity of SARS-CoV-2 Omicron variant. Nature 2022. 2022; p. 1-1. doi:10.1038/s41586-022-04462-1.

20. Yamasoba D, Kimura I, Nasser H, Morioka Y, Nao N, Ito J, et al. Virological characteristics of SARS-CoV-2 BA.2 variant. bioRxiv. 2022; p. 2022.02.14.480335. doi:10.1101/2022.02.14.480335.

21. Kumar S, Karuppanan K, Subramaniam G. Omicron (BA.1) and Sub-Variants (BA.1, BA.2 and BA.3) of SARS-CoV-2 Spike Infectivity and Pathogenicity: A Comparative Sequence and Structural-based Computational Assessment. bioRxiv. 2022; p. 2022.02.11.480029. doi:10.1101/2022.02.11.480029.

22. Sanjuán R, Domingo-Calap P. Mechanisms of viral mutation. Cellular and Molecular Life Sciences. 2016;73:4433. doi:10.1007/S00018-016-2299-6. 
23. BioRender;. Available from: https://biorender.com/

24. Vega E, Donaldson E, Huynh J, Barclay L, Lopman B, Baric R, et al. RNA Populations in Immunocompromised Patients as Reservoirs for Novel Norovirus Variants. Journal of Virology. 2014;88:14184. doi:10.1128/JVI.02494-14.

25. Eden JS, Chisholm RH, Bull RA, White PA, Holmes EC, Tanaka MM. Persistent infections in immunocompromised hosts are rarely sources of new pathogen variants. Virus Evolution. 2017;3:18. doi:10.1093/VE/VEX018.

26. Truong TT, Ryutov A, Pandey U, Yee R, Goldberg L, Bhojwani D, et al. Persistent SARS-CoV-2 infection and increasing viral variants in children and young adults with impaired humoral immunity. medRxiv. 2021; p. 2021.02.27.21252099. doi:10.1101/2021.02.27.21252099.

27. Karim F, Moosa M, Gosnell B, Cele S, Giandhari J, Pillay S, et al. Persistent SARS-CoV-2 infection and intra-host evolution in association with advanced HIV infection. medRxiv. 2021; p. 2021.06.03.21258228. doi:10.1101/2021.06.03.21258228.

28. Borges V, Isidro J, Cunha M, Cochicho D, Martins L, Banha L, et al. LongTerm Evolution of SARS-CoV-2 in an Immunocompromised Patient with Non-Hodgkin Lymphoma. mSphere. 2021;6. doi:10.1128/MSPHERE.0024421/SUPPL ${ }_{F}$ ILE/MSPHERE.00244 - 21 - ST002.PDF.

29. Emergence of $\mathrm{Y} 453 \mathrm{~F}$ and $69-70 \mathrm{HV}$ mutations in a lymphoma patient with long-term COVID-19 - SARS-CoV-2 coronavirus / nCoV-2019 Genomic Epidemiology - Virological;. Available from: https://virological.org/t/ emergence-of-y453f-and-69-70hv-mutations-in-a-lymphoma-patient-with-long 580.

30. Kemp SA, Collier DA, Datir RP, Ferreira IATM, Gayed S, Jahun A, et al. SARSCoV-2 evolution during treatment of chronic infection. Nature 2021 592:7853. 2021;592:277-282. doi:10.1038/s41586-021-03291-y.

31. Hayashi T, Gmrc D, Yaegashi N, Konishi I, Sci DM. Effect of RBD mutations in spike glycoprotein of SARS-CoV-2 on neutralizing IgG affinity. medRxiv. 2021; p. 2021.01.28.21250577. doi:10.1101/2021.01.28.21250577.

32. Sun Y, Lin W, Dong W, Xu J. Origin and evolutionary analysis of the SARSCoV-2 Omicron variant. Journal of Biosafety and Biosecurity. 2022;4:33-37. doi:10.1016/J.JOBB.2021.12.001.

33. Cameroni E, Bowen JE, Rosen LE, Saliba C, Zepeda SK, Culap K, et al. Broadly neutralizing antibodies overcome SARS-CoV-2 Omicron antigenic shift. Nature 2021. 2021;602:1-7. doi:10.1038/s41586-021-04386-2.

34. Wei C, Shan KJ, Wang W, Zhang S, Huan Q, Qian W. Evidence for a mouse origin of the SARS-CoV-2 Omicron variant. Journal of Genetics and Genomics. 2021;48:1111-1121. doi:10.1016/J.JGG.2021.12.003.

35. Kandeel M, Mohamed MEM, El-Lateef HMA, Venugopala KN, El-Beltagi HS. Omicron variant genome evolution and phylogenetics. Journal of Medical Virology. 2022;94:1627-1632. doi:10.1002/JMV.27515.

36. outbreak.info; Available from: https://outbreak.info/compare-lineages? gene=0RF1a\&gene=0RF1b\&gene=S\&gene=0RF3a\&gene=N\&threshold=50\& nthresh=1\&sub=false\&dark=true. 
37. CoVariants;. Available from: https://covariants.org/shared-mutations

38. Pattern Analysis Report: VOC Omicron - Stanford Coronavirus Antiviral Resistance Database (CoVDB);. Available from: https: //covdb.stanford.edu/sierra/sars2/by-patterns/report/?mutations= S $\% 3 A A 67 V \% 2 C S \% 3 A H 69 d e 1 \% 2 C S \% 3 A V 70 d e 1 \% 2 C S \% 3 A T 95 I \% 2 C S \% 3 A G 142 D \% 2 C S \%$ 3AV143del $\% 2$ CS $\% 3 A Y 144 d e 1 \% 2 C S \% 3 A Y 145$ del $\% 2 C S \% 3 A N 211$ I $\% 2 C S \% 3 A L 212 d e l \%$ 2CS $\% 3 A$ A214ins $\% 2$ CS $\% 3 A$ A339D $\% 2$ CS $\% 3 A S 371 \mathrm{~L} \% 2$ CS $\% 3$ AS373P $\% 2 C S \% 3 A S 375 F \%$ 2CS $\% 3 A K 417 N \% 2$ CS $\% 3 A N 440 K \% 2 C S \% 3 A G 446 S \% 2 C S \% 3 A S 477 N \% 2 C S \% 3 A T 478 K \%$ 2CS $\% 3 A E 484 A \% 2 C S \% 3 A Q 493 R \% 2 C S \% 3 A G 496 S \% 2 C S \% 3 A Q 498 R \% 2 C S \% 3 A N 501 Y \%$ 2CS $\% 3$ AY505H $\% 2$ CS $\% 3 A T 547 \mathrm{~K} \% 2$ CS $\% 3 A D 614 G \% 2 C S \% 3 A H 655 Y \% 2 C S \% 3 A N 679 K \%$ $2 \mathrm{CS} \% 3 \mathrm{AP} 681 \mathrm{H} \% 2 \mathrm{CS} \% 3 \mathrm{AA} 701 \mathrm{~V} \% 2 \mathrm{CS} \% 3 \mathrm{AN7} 64 \mathrm{~K} \% 2 \mathrm{CS} \% 3 \mathrm{AD} 796 \mathrm{Y} \% 2 \mathrm{CS} \% 3 \mathrm{AN} 856 \mathrm{~K} \% 2 \mathrm{CS} \%$ 3AQ954H $\% 2$ CS $\% 3 A N 969 K \% 2 C S \% 3 A L 981 F \& n a m e=V 0 C \% 200 m i c r o n$.

39. Harvey WT, Carabelli AM, Jackson B, Gupta RK, Thomson EC, Harrison EM, et al. SARS-CoV-2 variants, spike mutations and immune escape. Nature Reviews Microbiology 2021 19:7. 2021;19:409-424. doi:10.1038/s41579-021-00573-0.

40. Gupta D, Sharma P, Singh M, Kumar M, Ethayathulla AS, Kaur P. Structural and functional insights into the spike protein mutations of emerging SARS-CoV-2 variants. Cellular and Molecular Life Sciences 2021 78:24. 2021;78:7967-7989. doi:10.1007/S00018-021-04008-0.

41. Nelson G, Buzko O, Spilman P, Niazi K, Rabizadeh S, Soon-Shiong P. Molecular dynamic simulation reveals E484K mutation enhances spike RBD-ACE2 affinity and the combination of E484K, K417N and N501Y mutations (501Y.V2 variant) induces conformational change greater than N501Y mutant alone, potentially resulting in an escape mutant. bioRxiv. 2021; p. 2021.01.13.426558. doi:10.1101/2021.01.13.426558.

42. Ku Z, Xie X, Davidson E, Ye X, Su H, Menachery VD, et al. Molecular determinants and mechanism for antibody cocktail preventing SARS-CoV-2 escape. Nature Communications 2021 12:1. 2021;12:1-13. doi:10.1038/s41467020-20789-7.

43. Zahradník J, Marciano S, Shemesh M, Zoler E, Chiaravalli J, Meyer B, et al. SARS-CoV-2 RBD in vitro evolution follows contagious mutation spread, yet generates an able infection inhibitor. bioRxiv. 2021; p. 2021.01.06.425392. doi:10.1101/2021.01.06.425392.

44. Alouane T, Laamarti M, Essabbar A, Hakmi M, Bouricha EM, Chemao-Elfihri MW, et al. Genomic Diversity and Hotspot Mutations in 30,983 SARS-CoV2 Genomes: Moving Toward a Universal Vaccine for the "Confined Virus"? Pathogens 2020, Vol 9, Page 829. 2020;9:829. doi:10.3390/PATHOGENS9100829.

45. Fratev F. R346K Mutation in the $\mathrm{Mu}$ Variant of SARS-CoV-2 Alters the Interactions with Monoclonal Antibodies from Class 2: A Free Energy Perturbation Study. Journal of Chemical Information and Modeling. 2022;doi:10.1021/ACS.JCIM.1C01243/SUPPL ${ }_{F} I L E / C I 1 C 01243_{S} I_{0} 02 . Z I P$.

46. Sinha S, Tam B, Wang SM. Altered interaction between RBD and ACE2 receptor contributes towards the increased transmissibility of SARS CoV-2 delta, kappa, beta, and gamma strains with RBD double mutations. bioRxiv. 2021; p. 2021.08.30.458303. doi:10.1101/2021.08.30.458303. 
47. Núñez-Muñoz L, Marcelino-Pérez G, Calderón-Pérez B, Pérez-Saldívar M, Acosta-Virgen K, González-Conchillos H, et al. Recombinant Antigens Based on Non-Glycosylated Regions from RBD SARS-CoV-2 as Potential Vaccine Candidates against COVID-19. Vaccines 2021, Vol 9, Page 928. 2021;9:928. doi:10.3390/VACCINES9080928.

48. Verkhivker GM, Agajanian S, Oztas DY, Gupta G. Atomistic Simulations and in Silico Mutational Profiling of Protein Stability and Binding in the SARS-CoV-2 Spike Protein Complexes with Nanobodies: Molecular Determinants of Mutational Escape Mechanisms. ACS Omega. 2021;6:26354-26371. doi:10.1021/ACSOMEGA.1C03558/SUPPL ${ }_{F} I L E / A O 1 C 03558_{S} I_{0} 01 . P D F$.

49. Cao Y, Wang J, Jian F, Xiao T, Song W, Yisimayi A, et al. Omicron escapes the majority of existing SARS-CoV-2 neutralizing antibodies. bioRxiv. 2021; p. 2021.12.07.470392. doi:10.1101/2021.12.07.470392.

50. Liu L, Iketani S, Guo Y, Chan JFW, Wang M, Liu L, et al. Striking Antibody Evasion Manifested by the Omicron Variant of SARS-CoV-2. bioRxiv. 2021; p. 2021.12.14.472719. doi:10.1101/2021.12.14.472719.

51. Kumar S, Thambiraja TS, Karuppanan K, Subramaniam G. Omicron and Delta variant of SARS-CoV-2: A comparative computational study of spike protein. Journal of Medical Virology. 2022;94:1641-1649. doi:10.1002/JMV.27526.

52. Long SW, Olsen RJ, Christensen PA, Bernard DW, Davis JJ, Shukla M, et al. Molecular architecture of early dissemination and massive second wave of the SARS-CoV-2 virus in a major metropolitan area. mBio. 2020;11:1-30. doi:10.1128/MBIO.02707-20/SUPPL ${ }_{F} I L E / M B I O .02707-20-S F 006 . P D F$.

53. Zhang C, Wang Y, Zhu Y, Liu C, Gu C, Xu S, et al. Development and structural basis of a two-MAb cocktail for treating SARS-CoV-2 infections. Nature Communications 2021 12:1. 2021;12:1-16. doi:10.1038/s41467-020-20465-w.

54. VanBlargan LA, Adams LJ, Liu Z, Chen RE, Gilchuk P, Raju S, et al. A potently neutralizing SARS-CoV-2 antibody inhibits variants of concern by utilizing unique binding residues in a highly conserved epitope. Immunity. 2021;54:23992416.e6. doi:10.1016/J.IMMUNI.2021.08.016/ATTACHMENT/7E46D867-B6BF4AD1-9225-0910A493D882/MMC1.PDF.

55. Tortorici MA, Czudnochowski N, Starr TN, Marzi R, Walls AC, Zatta F, et al. Broad sarbecovirus neutralization by a human monoclonal antibody. Nature 2021 597:7874. 2021;597:103-108. doi:10.1038/s41586-021-03817-4.

56. Sztain T, Ahn SH, Bogetti AT, Casalino L, Goldsmith JA, Seitz E, et al. A glycan gate controls opening of the SARS-CoV-2 spike protein. Nature Chemistry 2021 13:10. 2021;13:963-968. doi:10.1038/s41557-021-00758-3.

57. Wang Z, Schmidt F, Weisblum Y, Muecksch F, Barnes CO, Finkin S, et al. mRNA vaccine-elicited antibodies to SARS-CoV-2 and circulating variants. bioRxiv. 2021; p. 2021.01.15.426911. doi:10.1101/2021.01.15.426911.

58. Tian F, Tong B, Sun L, Shi S, Zheng B, Wang Z, et al. N501y mutation of spike protein in sars-cov-2 strengthens its binding to receptor ace2. eLife. 2021;10. doi:10.7554/ELIFE.69091.

59. Verma J, Subbarao N. Insilico study on the effect of SARS-CoV-2 RBD hotspot mutants' interaction with ACE2 to understand the binding affinity and stability. Virology. 2021;561:107-116. doi:10.1016/J.VIROL.2021.06.009. 
60. Weisblum Y, Schmidt F, Zhang F, DaSilva J, Poston D, Lorenzi JCC, et al. Escape from neutralizing antibodies 1 by SARS-CoV-2 spike protein variants. eLife. 2020;9:1. doi:10.7554/ELIFE.61312.

61. Chen J, Wang R, Wang M, Wei GW. Mutations Strengthened SARSCoV-2 Infectivity. Journal of Molecular Biology. 2020;432:5212-5226. doi:10.1016/J.JMB.2020.07.009.

62. Giacomo SD, Mercatelli D, Rakhimov A, Giorgi FM. Preliminary report on severe acute respiratory syndrome coronavirus 2 (SARS-CoV-2) Spike mutation T478K. Journal of Medical Virology. 2021;93:5638-5643. doi:10.1002/JMV.27062.

63. Laurini E, Marson D, Aulic S, Fermeglia A, Pricl S. Molecular rationale for SARS-CoV-2 spike circulating mutations able to escape bamlanivimab and etesevimab monoclonal antibodies. Scientific Reports 2021 11:1. 2021;11:1-20. doi:10.1038/s41598-021-99827-3.

64. Focosi D, Novazzi F, Genoni A, Dentali F, Gasperina DD, Baj A, et al. Emergence of SARS-COV-2 Spike Protein Escape Mutation Q493R after Treatment for COVID-19. Emerging Infectious Diseases. 2021;27:2728. doi:10.3201/EID2710.211538.

65. Teng S, Sobitan A, Rhoades R, Liu D, Tang Q. Systemic effects of missense mutations on SARS-CoV-2 spike glycoprotein stability and receptor-binding affinity. Briefings in Bioinformatics. 2021;22:1239-1253. doi:10.1093/BIB/BBAA233.

66. Lan J, He X, Ren Y, Wang Z, Zhou H, Fan S, et al. Structural and computational insights into the SARS-CoV-2 Omicron RBD-ACE2 interaction. bioRxiv. 2022; p. 2022.01.03.474855. doi:10.1101/2022.01.03.474855.

67. Rahman MS, Islam MR, Hoque MN, Alam ASMRU, Akther M, Puspo JA, et al. Comprehensive annotations of the mutational spectra of SARS-CoV-2 spike protein: a fast and accurate pipeline. Transboundary and Emerging Diseases. 2021;68:1625-1638. doi:10.1111/TBED.13834.

68. Alkhatib M, Svicher V, Salpini R, Ambrosio FA, Bellocchi MC, Carioti L, et al. SARS-CoV-2 Variants and Their Relevant Mutational Profiles: Update Summer 2021. Microbiology Spectrum. 2021;9. doi:10.1128/SPECTRUM.0109621/SUPPL ${ }_{F} I L E / S P E C T R U M 01096-21_{S} U P P_{2 S} E Q 11 . X L S X$.

69. Klinakis A, Cournia Z, Rampias T. N-terminal domain mutations of the spike protein are structurally implicated in epitope recognition in emerging SARS-CoV2 strains. Computational and Structural Biotechnology Journal. 2021;19:55565567. doi:10.1016/J.CSBJ.2021.10.004.

70. Liu C, Ginn HM, Dejnirattisai W, Supasa P, Wang B, Tuekprakhon $\mathrm{A}$, et al. Reduced neutralization of SARS-CoV-2 B.1.617 by vaccine and convalescent serum. Cell. 2021;184:4220-4236.e13. doi:10.1016/J.CELL.2021.06.020/ATTACHMENT/10183911-F97E-4DA5AE05-227854F207F4/MMC1.PDF.

71. Bal A, Destras G, Gaymard A, Stefic K, Marlet J, Eymieux S, et al. Two-step strategy for the identification of SARS-CoV-2 variant of concern 202012/01 and other variants with spike deletion H69-V70, France, August to December 2020. Eurosurveillance. 2021;26:2100008. doi:10.2807/15607917.ES.2021.26.3.2100008/CITE/PLAINTEXT. 
72. Xie X, Liu Y, Liu J, Zhang X, Zou J, Fontes-Garfias CR, et al. Neutralization of SARS-CoV-2 spike 69/70 deletion, E484K and N501Y variants by BNT162b2 vaccine-elicited sera. Nature Medicine 2021 27:4. 2021;27:620-621. doi:10.1038/s41591-021-01270-4.

73. Meng B, Kemp SA, Papa G, Datir R, Ferreira IATM, Marelli S, et al. Recurrent emergence of SARS-CoV-2 spike deletion H69/V70 and its role in the Alpha variant B.1.1.7. Cell Reports. 2021;35. doi:10.1016/J.CELREP.2021.109292/ATTACHMENT/9EBB2AAF-08C849F6-9D59-BF93B6C81CC3/MMC1.PDF.

74. Kannan SR, Spratt AN, Cohen AR, Naqvi SH, Chand HS, Quinn TP, et al. Evolutionary analysis of the Delta and Delta Plus variants of the SARS-CoV-2 viruses. Journal of Autoimmunity. 2021;124:102715. doi:10.1016/J.JAUT.2021.102715.

75. Shen L, Triche TJ, Bard JD, Biegel JA, Judkins AR, Gai X. Spike Protein NTD mutation G142D in SARS-CoV-2 Delta VOC lineages is associated with frequent back mutations, increased viral loads, and immune evasion. medRxiv. 2021; p. 2021.09.12.21263475. doi:10.1101/2021.09.12.21263475.

76. Avanzato VA, Matson MJ, Seifert SN, Pryce R, Williamson BN, Anzick SL, et al. Case Study: Prolonged Infectious SARS-CoV-2 Shedding from an Asymptomatic Immunocompromised Individual with Cancer. Cell. 2020;183:1901. doi:10.1016/J.CELL.2020.10.049.

77. Identification of a new B.1.1.33 SARS-CoV-2 Variant of Interest (VOI) circulating in Brazil with mutation E484K and multiple deletions in the amino (N)-terminal domain of the Spike protein - SARS-CoV-2 coronavirus / nCoV-2019 Genomic Epidemiology - Virological;. Available from: https://virological.org/t/ identification-of-a-new-b-1-1-33-sars-cov-2-variant-of-interest-voi-cir 675 .

78. Haslwanter D, Dieterle ME, Wec AZ, O'brien CM, Sakharkar M, Florez C, et al. A Combination of Receptor-Binding Domain and N-Terminal Domain Neutralizing Antibodies Limits the Generation of SARS-CoV-2 Spike Neutralization-Escape Mutants. mBio. 2021;12. doi:10.1128/MBIO.02473-21/ASSET/14C2D4DB5027-42E3-A4F5-CE5103C95355/ASSETS/IMAGES/MEDIUM/MBIO.0247321-F005.GIF.

79. Yeh TY, Contreras GP. Tajima D test accurately forecasts Omicron / COVID-19 outbreak. medRxiv. 2021; p. 2021.12.02.21267185. doi:10.1101/2021.12.02.21267185.

80. Resende PC, Naveca FG, Lins RD, Dezordi FZ, Ferraz MVF, Moreira EG, et al. The ongoing evolution of variants of concern and interest of SARS-CoV-2 in Brazil revealed by convergent indels in the amino (N)-terminal domain of the spike protein. Virus Evolution. 2021;7. doi:10.1093/VE/VEAB069.

81. Gobeil SMC, Janowska K, McDowell S, Mansouri K, Parks R, Manne $\mathrm{K}$, et al. D614G Mutation Alters SARS-CoV-2 Spike Conformation and Enhances Protease Cleavage at the S1/S2 Junction. Cell Reports. 2021;34. doi:10.1016/J.CELREP.2020.108630/ATTACHMENT/F0D1DB24-50904B70-8DBD-86CCFD9FA526/MMC1.PDF.

82. Braun KM, Moreno GK, Halfmann PJ, Hodcroft EB, Baker DA, Boehm EC, et al. Transmission of SARS-CoV-2 in domestic cats imposes a narrow bottleneck. PLoS Pathogens. 2021;17. doi:10.1371/JOURNAL.PPAT.1009373. 
83. Emergence and spread of SARS-CoV-2 P.1 (Gamma) lineage variants carrying Spike mutations [U+1D6AB] 141-144, N679K or $\mathrm{P} 681 \mathrm{H}$ during persistent viral circulation in Amazonas, Brazil - SARS-CoV-2 coronavirus / nCoV-2019 Genomic Epidemiology - Virological;. Available from: https://virological.org/t/ emergence-and-spread-of-sars-cov-2-p-1-gamma-lineage-variants-carrying-s 722 .

84. Lubinski B, Fernandes MHV, Frazier L, Tang T, Daniel S, Diel DG, et al. Functional evaluation of the $\mathrm{P} 681 \mathrm{H}$ mutation on the proteolytic activation the SARS-CoV-2 variant B.1.1.7 (Alpha) spike. bioRxiv. 2021; p. 2021.04.06.438731. doi:10.1101/2021.04.06.438731.

85. Mallm JP, Bundschuh C, Kim H, Weidner N, Steiger S, Lander I, et al. Local emergence and decline of a SARS-CoV-2 variant with mutations L452R and N501Y in the spike protein. medRxiv. 2021; p. 2021.04.27.21254849. doi:10.1101/2021.04.27.21254849.

86. Sarkar R, Lo M, Saha R, Dutta S, Chawla-Sarkar M. S glycoprotein diversity of the Omicron variant. medRxiv. 2021; p. 2021.12.04.21267284. doi:10.1101/2021.12.04.21267284.

87. Ramirez S, Fernandez-Antunez C, Galli A, Underwood A, Pham LV, Ryberg LA, et al. Overcoming culture restriction for SARS-CoV-2 in human cells facilitates the screening of compounds inhibiting viral replication. Antimicrobial Agents and Chemotherapy. 2021;65. doi:10.1128/AAC.00097-21/ASSET/2FC69DE2B083-4037-9D1F-9FF4E0035223/ASSETS/IMAGES/LARGE/AAC.00097-21F006.JPG.

88. Timmers LFSM, Peixoto JV, Ducati RG, Bachega JFR, de Mattos Pereira L, Caceres RA, et al. SARS-CoV-2 mutations in Brazil: from genomics to putative clinical conditions. Scientific Reports 2021 11:1. 2021;11:1-14. doi:10.1038/s41598021-91585-6.

89. Mou K, Abdalla M, Wei DQ, Khan MT, Lodhi MS, Darwish DB, et al. Emerging mutations in envelope protein of SARS-CoV-2 and their effect on thermodynamic properties. Informatics in Medicine Unlocked. 2021;25:100675. doi:10.1016/J.IMU.2021.100675.

90. Troyano-Hernáez P, Reinosa R, África Holguín. Evolution of SARS-CoV-2 Envelope, Membrane, Nucleocapsid, and Spike Structural Proteins from the Beginning of the Pandemic to September 2020: A Global and Regional Approach by Epidemiological Week. Viruses 2021, Vol 13, Page 243. 2021;13:243. doi:10.3390/V13020243.

91. Bianchi M, Benvenuto D, Giovanetti M, Angeletti S, Ciccozzi M, Pascarella S. Sars-CoV-2 Envelope and Membrane Proteins: Structural Differences Linked to Virus Characteristics? BioMed Research International. 2020;2020. doi:10.1155/2020/4389089.

92. Oulas A, Zanti M, Tomazou M, Zachariou M, Minadakis G, Bourdakou $\mathrm{MM}$, et al. Generalized linear models provide a measure of virulence for specific mutations in SARS-CoV-2 strains. PLOS ONE. 2021;16:e0238665. doi:10.1371/JOURNAL.PONE.0238665.

93. Perdikari TM, Murthy AC, Ryan VH, Watters S, Naik MT, Fawzi NL. SARSCoV-2 nucleocapsid protein phase-separates with RNA and with human hnRNPs. The EMBO Journal. 2020;39:e106478. doi:10.15252/EMBJ.2020106478. 
94. Leary S, Gaudieri S, Parker MD, Chopra A, James I, Pakala S, et al. Generation of a novel SARS-CoV-2 sub-genomic RNA due to the R203K/G204R variant in nucleocapsid. bioRxiv. 2021; p. 2020.04.10.029454. doi:10.1101/2020.04.10.029454.

95. Mourier T, Shuaib M, Hala S, Mfarrej S, Alofi F, Naeem R, et al. Saudi Arabian SARS-CoV-2 genomes implicate a mutant Nucleocapsid protein in modulating host interactions and increased viral load in COVID-19 patients. medRxiv. 2021; p. 2021.05.06.21256706. doi:10.1101/2021.05.06.21256706.

96. Ádám Nagy, Pongor S, Győrffy B. Different mutations in SARS-CoV-2 associate with severe and mild outcome. International Journal of Antimicrobial Agents. 2021;57:106272. doi:10.1016/J.IJANTIMICAG.2020.106272.

97. Ju X, Zhu Y, Wang Y, Li J, Zhang J, Gong M, et al. A novel cell culture system modeling the SARS-CoV-2 life cycle. PLOS Pathogens. 2021;17:e1009439. doi:10.1371/JOURNAL.PPAT.1009439.

98. Sakuraba S, Qilin X, Kasahara K, Iwakiri J, Kono H. Modeling the SARS-CoV-2 nsp1-5'-UTR complex via extended ensemble simulations. bioRxiv. 2021; p. 2021.02.24.432807. doi:10.1101/2021.02.24.432807.

99. Jiang Y, Tong K, Yao R, Zhou Y, Lin H, Du L, et al. Genome-wide analysis of protein-protein interactions and involvement of viral proteins in SARS-CoV-2 replication. Cell and Bioscience. 2021;11:1-16. doi:10.1186/S13578-021-00644Y/FIGURES/6.

100. Sant'Anna FH, Varela APM, Prichula J, Comerlato J, Comerlato CB, Roglio VS, et al. Emergence of the novel SARSCoV-2 lineage VUI-NP13L and massive spread of P.2 in South Brazil. Emerging Microbes and Infections. 2021;10:1431-1440. doi:10.1080/22221751.2021.1949948/SUPPL ${ }_{F} I L E / T E M I_{A 1} 9^{949948_{S} M 7921 . D O C X}$.

101. Sarkar R, Saha R, Mallick P, Sharma R, Kaur A, Dutta S, et al. Emergence of a novel SARS-CoV-2 Pango lineage B.1.1.526 in West Bengal, India. Journal of Infection and Public Health. 2022;15:42-50. doi:10.1016/J.JIPH.2021.11.020.

102. Ahmed-Abakur EH, Alnour TMS. Genetic variations among SARSCoV-2 strains isolated in China. Gene Reports. 2020;21:100925. doi:10.1016/J.GENREP.2020.100925.

103. Khailany RA, Safdar M, Ozaslan M. Genomic characterization of a novel SARSCoV-2. Gene Reports. 2020;19:100682. doi:10.1016/J.GENREP.2020.100682.

104. Anjos D, Fiaccadori FS, do Prado Servian C, da Fonseca SG, Guilarde AO, Borges MASB, et al. SARS-CoV-2 loads in urine, sera and stool specimens in association with clinical features of COVID-19 patients. Journal of Clinical Virology Plus. 2022;2:100059. doi:10.1016/J.JCVP.2021.100059.

105. Vilar S, Isom DG. One Year of SARS-CoV-2: How Much Has the Virus Changed? Biology 2021, Vol 10, Page 91. 2021;10:91. doi:10.3390/BIOLOGY10020091.

106. Benvenuto D, Angeletti S, Giovanetti M, Bianchi M, Pascarella S, Cauda R, et al. Evolutionary analysis of SARS-CoV-2: how mutation of Non-Structural Protein 6 (NSP6) could affect viral autophagy. Journal of Infection. 2020;81:e24-e27. doi:10.1016/J.JINF.2020.03.058. 
107. Santerre M, Arjona SP, Allen CN, Shcherbik N, Sawaya BE. Why do SARSCoV-2 NSPs rush to the ER? Journal of Neurology. 2021;268:2013-2022. doi:10.1007/S00415-020-10197-8/FIGURES/4.

108. Franceschi VB, Caldana GD, Perin C, Horn A, Peter C, Cybis GB, et al. Predominance of the SARS-CoV-2 Lineage P.1 and Its Sublineage P.1.2 in Patients from the Metropolitan Region of Porto Alegre, Southern Brazil in March 2021. Pathogens 2021, Vol 10, Page 988. 2021;10:988. doi:10.3390/PATHOGENS10080988.

109. Zimerman RA, Aline P, Ferrareze G, Cadegiani FA, Wambier CG, Do D, et al. Comparative genomics and characterization of SARS-CoV-2 P.1 (Gamma) Variant of Concern (VOC) from Amazonas, Brazil. medRxiv. 2021; p. 2021.10.30.21265694. doi:10.1101/2021.10.30.21265694.

110. Sun X, Yu J, Wong SH, Chan MTV, Zhang L, Wu WKK. SARSCoV-2 targets the lysosome to mediate airway inflammatory cell death. https://doiorg/101080/1554862720212021496. 2022; p. 1-3. doi:10.1080/15548627.2021.2021496.

111. Sahin E, Bozdayi G, Yigit S, Muftah H, Dizbay M, Tunccan OG, et al. Genomic characterization of SARS-CoV-2 isolates from patients in Turkey reveals the presence of novel mutations in spike and nsp12 proteins. Journal of Medical Virology. 2021;93:6016-6026. doi:10.1002/JMV.27188.

112. Biswas SK, Mudi SR. Spike protein D614G and RdRp P323L: the SARS-CoV2 mutations associated with severity of COVID-19. Genomics Informatics. 2020;18:1-7. doi:10.5808/GI.2020.18.4.E44.

113. Sengupta A, Hassan SS, Choudhury PP. Clade GR and clade GH isolates of SARS-CoV-2 in Asia show highest amount of SNPs. Infection, Genetics and Evolution. 2021;89:104724. doi:10.1016/J.MEEGID.2021.104724.

114. Kumar S, Azad GK. An immunoinformatics approach to study the epitopes contributed by Nsp13 of SARS-CoV-2. bioRxiv. 2021; p. 2021.04.02.438155. doi:10.1101/2021.04.02.438155.

115. Martin R, Li J, Parvangada A, Perry J, Cihlar T, Mo H, et al. Genetic conservation of SARS-CoV-2 RNA replication complex in globally circulating isolates and recently emerged variants from humans and minks suggests minimal pre-existing resistance to remdesivir. Antiviral Research. 2021;188:105033. doi:10.1016/J.ANTIVIRAL.2021.105033.

116. Kern DM, Sorum B, Mali SS, Hoel CM, Sridharan S, Remis JP, et al. Cryo-EM structure of SARS-CoV-2 ORF3a in lipid nanodiscs. Nature Structural Molecular Biology 2021 28:7. 2021;28:573-582. doi:10.1038/s41594-021-00619-0.

117. Jauregui AR, Savalia D, Lowry VK, Farrell CM, Wathelet MG. Identification of Residues of SARS-CoV nsp1 That Differentially Affect Inhibition of Gene Expression and Antiviral Signaling. PLoS ONE. 2013;8:62416. doi:10.1371/JOURNAL.PONE.0062416.

118. Schubert K, Karousis ED, Jomaa A, Scaiola A, Echeverria B, Gurzeler LA, et al. SARS-CoV-2 Nsp1 binds the ribosomal mRNA channel to inhibit translation. Nature structural molecular biology. 2020;27:959-966. doi:10.1038/S41594-0200511-8. 
119. Mou K, Mukhtar F, Khan MT, Darwish DB, Peng S, Muhammad S, et al. Emerging mutations in nsp1 of sars-cov-2 and their effect on the structural stability. Pathogens. 2021;10. doi:10.3390/PATHOGENS10101285/S1.

120. Sakai Y, Kawachi K, Terada Y, Omori H, Matsuura Y, Kamitani W. Two-amino acids change in the nsp4 of SARS coronavirus abolishes viral replication. Virology. 2017;510:165. doi:10.1016/J.VIROL.2017.07.019.

121. Khan MT, Zeb MT, Ahsan H, Ahmed A, Ali A, Akhtar K, et al. SARS-CoV-2 nucleocapsid and Nsp3 binding: an in silico study. Archives of Microbiology. 2021;203:59-66. doi:10.1007/S00203-020-01998-6/FIGURES/3.

122. Frieman M, Ratia K, Johnston RE, Mesecar AD, Baric RS. Severe Acute Respiratory Syndrome Coronavirus Papain-Like Protease Ubiquitin-Like Domain and Catalytic Domain Regulate Antagonism of IRF3 and NF-B Signaling. Journal of Virology. 2009;83:6689. doi:10.1128/JVI.02220-08.

123. Angeletti S, Benvenuto D, Bianchi M, Giovanetti M, Pascarella S, Ciccozzi M. COVID [U+2010] 2019: The role of the nsp2 and nsp3 in its pathogenesis. Journal of Medical Virology. 2020;92:584-588. doi:10.1002/JMV.25719.

124. Forni D, Cagliani R, Mozzi A, Pozzoli U, Al-Daghri N, Clerici M, et al. Extensive Positive Selection Drives the Evolution of Nonstructural Proteins in Lineage C Betacoronaviruses. Journal of Virology. 2016;90:3627. doi:10.1128/JVI.02988-15.

125. V'kovski P, Kratzel A, Steiner S, Stalder H, Thiel V. Coronavirus biology and replication: implications for SARS-CoV-2. Nature Reviews Microbiology. 2021;19:155. doi:10.1038/S41579-020-00468-6.

126. Arya R, Kumari S, Pandey B, Mistry H, Bihani SC, Das A, et al. Structural insights into SARS-CoV-2 proteins. Journal of Molecular Biology. 2021;433:166725. doi:10.1016/J.JMB.2020.11.024.

127. Liu Y, Qin C, Rao Y, Ngo C, Feng JJ, Zhao J, et al. SARS-CoV-2 Nsp5 Demonstrates Two Distinct Mechanisms Targeting RIG-I and MAVS to Evade the Innate Immune Response. mBio. 2021;12. doi:10.1128/MBIO.0233521/SUPPL ${ }_{F} I L E / M B I O .02335-21-S F 007 . J P G$.

128. Pachetti M, Marini B, Benedetti F, Giudici F, Mauro E, Storici P, et al. Emerging SARS-CoV-2 mutation hot spots include a novel RNA-dependentRNA polymerase variant. Journal of Translational Medicine. 2020;18:179. doi:10.1186/S12967-020-02344-6.

129. Wang R, Hozumi Y, Yin C, Wei GW. Decoding SARS-CoV-2 Transmission and Evolution and Ramifications for COVID-19 Diagnosis, Vaccine, and Medicine. Journal of Chemical Information and Modeling. 2020;60:5853-5865. doi:10.1021/ACS.JCIM.0C00501/SUPPL ${ }_{F} I L E / C I 0 C 00501_{S} I_{0} 02 . X L S X$.

130. Majumdar P, Niyogi S. SARS-CoV-2 mutations: the biological trackway towards viral fitness. Epidemiology and Infection. 2021;149. doi:10.1017/S0950268821001060.

131. Gorkhali R, Koirala P, Rijal S, Mainali A, Baral A, Bhattarai HK. Structure and Function of Major SARS-CoV-2 and SARSCoV Proteins:. $\quad$ https://doiorg/101177/11779322211025876. 2021;15. doi:10.1177/11779322211025876. 
132. Ma Y, Wu L, Shaw N, Gao Y, Wang J, Sun Y, et al. Structural basis and functional analysis of the SARS coronavirus nsp14-nsp10 complex. Proceedings of the National Academy of Sciences of the United States of America. 2015;112:94369441. doi:10.1073/PNAS.1508686112/-/DCSUPPLEMENTAL.

133. Yuen CK, Lam JY, Wong WM, Mak LF, Wang $\mathrm{X}$, Chu $\mathrm{H}$, et al. SARS-CoV-2 nsp13, nsp14, nsp15 and orf6 function as potent interferon antagonists. Emerging Microbes and Infections. 2020;9:1418-1428. doi:10.1080/22221751.2020.1780953/SUPPL ${ }_{F} I L E / T E M I_{A 1} 780953_{S} M 1758 . Z I P$.

134. Ricagno S, Egloff MP, Ulferts R, Coutard B, Nurizzo D, Campanacci V, et al. Crystal structure and mechanistic determinants of SARS coronavirus nonstructural protein 15 define an endoribonuclease family. Proceedings of the National Academy of Sciences. 2006;103:11892-11897. doi:10.1073/PNAS.0601708103.

135. Deng X, Hackbart M, Mettelman RC, O'Brien A, Mielech AM, Yi G, et al. Coronavirus nonstructural protein 15 mediates evasion of dsRNA sensors and limits apoptosis in macrophages. Proceedings of the National Academy of Sciences of the United States of America. 2017;114:E4251-E4260. doi:10.1073/PNAS.1618310114/-/DCSUPPLEMENTAL.

136. Lu B, Tao L, Wang T, Zheng Z, Li B, Chen Z, et al. Humoral and cellular immune responses induced by 3 a DNA vaccines against severe acute respiratory syndrome (SARS) or SARS-like coronavirus in mice. Clinical and Vaccine Immunology. 2009;16:73-77. doi:10.1128/CVI.00261-08/ASSET/F6406B7F-0692-4156-BAF3176C48FB2548/ASSETS/GRAPHIC/ZCD0010934200004.JPEG.

137. Jakhmola S, Indari O, Kashyap D, Varshney N, Das A, Manivannan E, et al. Mutational analysis of structural proteins of SARS-CoV-2. Heliyon. 2021;7:e6572. doi:10.1016/J.HELIYON.2021.E06572.

138. Wu Q, Zhang Y, Lü H, Wang J, He X, Liu Y, et al. The E Protein Is a Multifunctional Membrane Protein of SARS-CoV. Genomics, Proteomics Bioinformatics. 2003;1:131-144. doi:10.1016/S1672-0229(03)01017-9.

139. DeDiego ML, Nieto-Torres JL, Jimenez-Guardeño JM, Regla-Nava JA, CastañoRodriguez C, Fernandez-Delgado R, et al. Coronavirus virulence genes with main focus on SARS-CoV envelope gene. Virus Research. 2014;194:124. doi:10.1016/J.VIRUSRES.2014.07.024.

140. Syed AM, Taha TY, Tabata T, Chen IP, Ciling A, Khalid MM, et al. Rapid assessment of SARS-CoV-2-evolved variants using virus-like particles. Science (New York, NY). 2021;374:1626-1632. doi:10.1126/SCIENCE.ABL6184.

141. Waterhouse A, Bertoni M, Bienert S, Studer G, Tauriello G, Gumienny R, et al. SWISS-MODEL: homology modelling of protein structures and complexes. Nucleic Acids Research. 2018;46:W296-W303. doi:10.1093/NAR/GKY427.

142. Parvez MSA, Saha MK, Ibrahim M, Araf Y, Islam MT, Ohtsuki G, et al. Insights from a computational analysis of the SARS-CoV-2 Omicron variant: Hostpathogen interaction, pathogenicity and possible therapeutics. 2022;.

143. Rehman Z, Umair M, Ikram A, Salman M, Haider SA, Ammar M. A Computational Dissection of Spike protein of SARS-CoV-2 Omicron Variant. bioRxiv. 2021; p. 2021.12.17.473260. doi:10.1101/2021.12.17.473260.

144. Schrödinger L, DeLano W. PyMOL - www.pymol.org;. Available from: https: //www.pymol.org/pymol.html? 